\title{
Shifts in coastal sediment oxygenation cause pronounced changes in microbial community composition and associated metabolism
}

\author{
Elias Broman ${ }^{1 *}$, Johanna Sjöstedt ${ }^{1,2,3}$, Jarone Pinhassi $^{1}$ and Mark Dopson ${ }^{1}$
}

\begin{abstract}
Background: A key characteristic of eutrophication in coastal seas is the expansion of hypoxic bottom waters, often referred to as 'dead zones'. One proposed remediation strategy for coastal dead zones in the Baltic Sea is to mix the water column using pump stations, circulating oxygenated water to the sea bottom. Although microbial metabolism in the sediment surface is recognized as key in regulating bulk chemical fluxes, it remains unknown how the microbial community and its metabolic processes are influenced by shifts in oxygen availability. Here, coastal Baltic Sea sediments sampled from oxic and anoxic sites, plus an intermediate area subjected to episodic oxygenation, were experimentally exposed to oxygen shifts. Chemical, 16S rRNA gene, metagenomic, and metatranscriptomic analyses were conducted to investigate changes in chemistry fluxes, microbial community structure, and metabolic functions in the sediment surface.
\end{abstract}

Results: Compared to anoxic controls, oxygenation of anoxic sediment resulted in a proliferation of bacterial populations in the facultative anaerobic genus Sulfurovum that are capable of oxidizing toxic sulfide. Furthermore, the oxygenated sediment had higher amounts of RNA transcripts annotated as sqr, fccB, and $d s r A$ involved in sulfide oxidation. In addition, the importance of cryptic sulfur cycling was highlighted by the oxidative genes listed above as well as $d s v A, \operatorname{ttr} B, d m s A$, and $d d h A B$ that encode reductive processes being identified in anoxic and intermediate sediments turned oxic. In particular, the intermediate site sediments responded differently upon oxygenation compared to the anoxic and oxic site sediments. This included a microbial community composition with more habitat generalists, lower amounts of RNA transcripts attributed to methane oxidation, and a reduced rate of organic matter degradation.

Conclusions: These novel data emphasize that genetic expression analyses has the power to identify key molecular mechanisms that regulate microbial community responses upon oxygenation of dead zones. Moreover, these results highlight that microbial responses, and therefore ultimately remediation efforts, depend largely on the oxygenation history of sites. Furthermore, it was shown that re-oxygenation efforts to remediate dead zones could ultimately be facilitated by in situ microbial molecular mechanisms involved in removal of toxic $\mathrm{H}_{2} \mathrm{~S}$ and the potent greenhouse gas methane.

Keywords: $16 \mathrm{~S}$ rRNA, Anoxic, Oxic, Metagenomics, Metatranscriptomics, Sediment

\footnotetext{
* Correspondence: elias.broman@Inu.se

${ }^{1}$ Centre for Ecology and Evolution in Microbial Model Systems (EEMiS),

Linnaeus University, Kalmar, Sweden

Full list of author information is available at the end of the article
} 


\section{Background}

Dissolved oxygen in the oceans has declined in the past five decades, and the decrease is accelerated by an increase in temperature. In conjunction with this decline, an expansion of oxygen-minimum-zones in the oceans has been observed. With an increase in ocean water temperature, climate change is suggested to further enhance this decrease of oxygen [1]. The expansion of episodic and persistent hypoxic areas, often referred to as 'dead zones', is altering ecosystem functioning of coastal systems largely as a result of eutrophication [2]. The negative influence of hypoxia on higher trophic levels is evident by damage to fisheries via increased fish mortality [3]. The provision of nutrients from eutrophication events fuels phytoplankton blooms that eventually die, and a portion of the biomass sinks to the sediment surface where it is degraded by aerobic microbes [4]. These metabolic processes deplete the available oxygen [5] such that the sediments and the overlying bottom water become anoxic. The oxygen depletion of sediments inhibits life for many macro and microorganisms, although anaerobic microbes still thrive (e.g., [6-8]). Given the importance of oxygenation levels for chemical fluxes between the sedimentwater interface and the preference of many microorganisms for either oxic or anoxic conditions [9], it is expected that many (bio)chemical pathways mediated by microorganisms are significantly affected by oxygen fluctuations. However, details on the molecular mechanisms regulating biogeochemical energy and nutrient cycles under fluctuating oxygen conditions remain largely unexplored.

In the Baltic Sea, hypoxic $(<2 \mathrm{mg} / \mathrm{L})$ sediment zones that persist during the whole year are currently about 10 -fold more widespread compared to 100 years ago [10]. The area of Baltic Sea episodic hypoxic and anoxic coastal zones has also increased during the last decades. Oxygen availability in Baltic Sea dead zones fluctuates over time due to the inflow of high saline, oxygen-rich water. The occurrences of these inflows are less common compared to three decades ago, and many previously oxygenated bottom sediments are instead rich in hydrogen sulfide $\left(\mathrm{H}_{2} \mathrm{~S}\right)$ [11].

Microbial communities in sediments are stratified due to the availability of electron acceptors that are utilized according to the energy gain, from most to least $[6,12]$ : $\mathrm{O}_{2}, \mathrm{NO}_{3}^{-}, \mathrm{Mn}^{3+}$ and $\mathrm{Mn}^{4+}$ oxides, $\mathrm{Fe}^{3+}$ oxides, and $\mathrm{SO}_{4}^{2-}$. This use of alternative electron acceptors in turn influences the oxygen-reduction potential at various depths in the sediment. Analysis of sediments from around the world has identified key microbial taxa associated with these redox reactions [13-15]. The microbial reduction of $\mathrm{Fe}^{3+}$ and $\mathrm{SO}_{4}^{2-}$ produces ferrous iron $\left(\mathrm{Fe}^{2+}\right)$ and toxic $\mathrm{H}_{2} \mathrm{~S}$, respectively, that can subsequently chemically precipitate as iron sulfides. This gives anoxic sediments their distinctive black color [6]. Conversion of previously oxic sediments to anoxic conditions would result in the production of $\mathrm{H}_{2} \mathrm{~S}$ while re-oxygenation of these areas would potentially detoxify the $\mathrm{H}_{2} \mathrm{~S}$ and facilitate the reestablishment of benthic micro and macroorganisms. Knowledge of how microbial community composition changes during fluctuations in oxygen levels would aid in interpreting the consequences of bulk chemical changes in the sediment.

The dominant microbial processes in anoxic sediments are heterotrophic/autotrophic sulfate reduction with methanogenesis occurring below the $\mathrm{SO}_{4}^{2-}$ reduction zone [6]. The reduced products $\left(\mathrm{Mn}^{2+}, \mathrm{Fe}^{2+}\right.$, and $\left.\mathrm{S}^{2-}\right)$ are released into the sediment pore-water where they diffuse upwards and can be consumed, e.g., by aerobic $\mathrm{H}_{2} \mathrm{~S}$ and $\mathrm{Fe}^{2+}$ oxidation or anaerobic denitrification [6, 16, 17]. These processes form vertical redox zones in the sediment that may constitute just a few hundred $\mu \mathrm{m}[5,18,19]$. Lower dissolved oxygen concentrations in the overlying water also cause redox layers to migrate upwards in the sediment [20]. Due to the difference in energy yield from available oxidations, organic matter is preserved in oxygen deficient sediments [21], and its degradation is slower compared to oxic sediments [22, 23]. Although it is known that the old and buried organic matter is rapidly degraded upon re-oxygenation, the time scales required to remove the organic matter and to detoxify the waters remain little studied.

Microbial communities in anoxic marine sediments are rich in Gamma and Deltaproteobacteria related to sulfate reduction (e.g., [24, 25]). In addition, identification of the microbial community structure in $\mathrm{O}_{2}$ rich, hypoxic, and anoxic surficial sediments has been conducted worldwide, including in the Baltic Sea (e.g., [7, 26-28]). Identification of sediment microbial communities along an eutrophication gradient in the Baltic Sea reveals patterns among major microbial groups and that Planctomycetes and Betaproteobacteria were more abundant in oxygen rich compared to oxygen deficient sediments [27]. In general, how the majority of the microbial community and its metabolism adapts to in situ shifts in oxygen concentration has not been identified.

In this study, we used complete sediment cores in a novel oxygen shift experimental design to investigate the impact of altering oxidative and reductive conditions in coastal Baltic Sea sediments exposed to seasonal transitions, i.e., oxic all-year-round, anoxic benthic water all-year-round, and an area that alternates between oxic and anoxic depending on the timeof-year. The aims of the study were (1) to link the microbial community structure to changing metabolic pathways in the sediment surface and benthic water as a result of oxygen shifts; (2) to investigate if associated shifts in metabolic strategies and functions regulate chemical fluxes; and (3) to elucidate how the chemical 
fluxes are affected by the oxygen in the benthic water and sediment surface.

\section{Methods \\ Sampling and handling of sediment cores}

Sampling was conducted in a Baltic Sea bay close to Loftahammar, Sweden on November 18, 2013. The studied bay was chosen as it contained sampling sites with different oxygenation histories based upon previous measurements of dissolved bottom water oxygen in the area and an earlier pilot study (full details in Additional file 1: Text S1). At the time of sampling, three sites were chosen: (1) a 6.5-m-deep (from water to sediment surface) site with long-term oxic sediment (brown sediment), $6.5{ }^{\circ} \mathrm{C}$ and $11.3 \mathrm{mg} / \mathrm{L} \mathrm{O}_{2}$ in the bottom water, located at WGS 57 53.214, 16 35.934; (2) a 31-m-deep site with long-term anoxic sediment (black sediment with a strong smell of $\left.\mathrm{H}_{2} \mathrm{~S}\right), 2.6{ }^{\circ} \mathrm{C}$ and $0.85 \mathrm{mg} / \mathrm{L}$ $\mathrm{O}_{2}$, WGS 57 53.531, 16 35.165; and (3) a 21-m-deep site in an intermediate zone between the two (predominantly black sediment with patches of brown), $2.8^{\circ} \mathrm{C}$ and $0.8 \mathrm{mg} /$ $\mathrm{L} \mathrm{O}_{2}$, WGS 57 53.545, 16 35.476.

Sediments were sampled using a gravity corer $(60-\mathrm{cm}-$ long polymethylmethacrylate tubes with an inner diameter of $7 \mathrm{~cm})$. The sediment $(27.5$ to $33.5 \mathrm{~cm}$ height) was collected with the overlying bottom water. Sediment cores were sealed at the top and bottom with polyoxymethylene lids with nitrile o-rings. To determine the chemistry and the microbial communities in the sediment at the time of sampling, three sediment cores were immediately tested for each site (nine in total). Bottom water overlying the sediment (approximately $50 \mathrm{~cm}$ above) was collected using a $2 \mathrm{~L}$ Ruttner water sampler (SWEDAQ HB). Bottom water temperature and dissolved oxygen were measured in the field using in situ sensors (WTW Multiline; full details in Additional file 1: Text S1). From the overlying water, $50 \mathrm{~mL}$ was aseptically transferred into a sterile tube and kept on ice for subsequent DNA extraction. In addition, a $15 \mathrm{~mL}$ sterile tube was filled to the cap and stored on ice for measurement of $\mathrm{Fe}^{2+}, \mathrm{Fe}^{3+}, \mathrm{SO}_{4}^{2-}, \mathrm{PO}_{4}^{3-}, \mathrm{NO}_{2}^{-}$in conjunction with $\mathrm{NO}_{3}^{-}$, reduced sulfur compounds, $\mathrm{pH}$, and redox potential. The cores were transported to the laboratory at $\sim 7{ }^{\circ} \mathrm{C}$ and were stored closed for 1 day in incubation temperature $\left(8{ }^{\circ} \mathrm{C}\right)$ prior to start of the experiments. An overview of the chemistry and nucleic acid extractions conducted during the incubation is presented below. To verify the microbial community composition responses to oxygenation, complementary samples for 16S rRNA gene operational taxonomic unit (OTU) analysis were collected during an experiment in May 2014 by sampling sediment cores from the anoxic field site, out of which five cores were maintained anoxic and five cores were turned oxic (full details of sampling and incubation procedure in [29]).

\section{Incubation of sediment cores}

Sixteen sediment cores were incubated in darkness for 21 days at $8{ }^{\circ} \mathrm{C}$. The cores were incubated at $8{ }^{\circ} \mathrm{C}$ as this was similar to the surface water temperature of $6.5{ }^{\circ} \mathrm{C}$ and re-oxygenation of the anoxic sediments occurs naturally by complete mixing of the water column or artificially by pumping of surface waters to the sea floor. Cores turned or maintained oxic were oxygenated by aerating the overlying water on top of the sediment during the whole experiment. This resulted in $\sim 10 \mathrm{mg} / \mathrm{L}$ $\mathrm{O}_{2}$ in the water phase of the 'anoxic-to-oxic' $(n=3)$, intermediate-to-oxic $(n=3)$, and oxic control $(n=2)$. Cores were turned or maintained anoxic by bubbling the overlying water with $\mathrm{N}_{2}$-gas for $45 \mathrm{~min}$ at the start of the incubation. This resulted in $\mathrm{O}_{2}$ concentrations below $0.1 \mathrm{mg} / \mathrm{L}$ (oxygen electrode, Innovative Instruments in the 'oxic-to-anoxic' $(n=2)$, intermediate-to-anoxic $(n=3)$, and 'anoxic control' $(n=2)$. To ensure that water sub-sampled for chemistry measurements and DNA extraction was homogenized, the water phase in each sediment core was mixed using magnets in sterile tubes suspended in the water that were agitated using magnets rotating outside the sediment cores. The water phase was sub-sampled approximately every fourth day throughout the incubation, while the $0-1 \mathrm{~cm}$ sediment surface was sliced after 21 days of incubation.

\section{Sub-sampling and chemistry measurements}

Sub-sampling of the anoxic cores briefly exposed the water surface to oxygen and therefore, they were subsequently bubbled with $\mathrm{N}_{2}$-gas for 1 to $5 \mathrm{~min}$ and the $\mathrm{O}_{2}$ concentration in the water phase confirmed to be $<0.1 \mathrm{mg} / \mathrm{L}$. That the mixing and aeration methodology oxygenated the water phase and surficial sediment was confirmed in eight separate oxic control sediment cores with an identical set-up using an optical oxygen meter attached to a motorized micromanipulator (FireStingO2; OXR50 oxygen sensor; Micromanipulator MU1, Pyroscience), and further verified in another experiment conducted during May 2014 using a similar incubation setup (see [29]). The oxygen penetration depth in the sediment surface was not measured in this experiment, but was confirmed to be $\sim 1.5 \mathrm{~mm}$ in an additional experiment conducted in April 2016 (15 days of incubation with a similar setup at $8{ }^{\circ} \mathrm{C}$ in darkness; determined with the optical oxygen meter attached to the motorized micromanipulator).

Sub-samples taken for analysis were (1) $4.5 \mathrm{~mL}$ sedi-

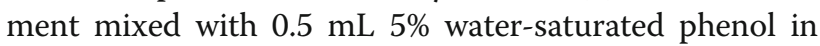
absolute ethanol [30], flash frozen in liquid nitrogen, and later used to extract RNA; (2) $10 \mathrm{~mL}$ sediment was stored on ice and used for DNA extraction (16S rRNA gene and metagenomics); (3) $5 \mathrm{~mL}$ sediment used for total pore-water iron; (4) $1 \mathrm{~mL}$ sediment transferred into 
a pre-weighed $2 \mathrm{~mL}$ polypropylene tube used to estimate sediment organic matter (\% $\mathrm{wt}$ ); and (5) the remaining sediment was retained for measurement of $\mathrm{SO}_{4}^{2-}, \mathrm{PO}_{4}^{3-}$, $\mathrm{NO}_{2}^{-}+\mathrm{NO}_{3}^{-}$, reduced sulfur compounds, $\mathrm{pH}$, and redox potential. Sediment slices for DNA and RNA were stored at $-80{ }^{\circ} \mathrm{C}$ until extracted. $50 \mathrm{~mL}$ of water for DNA extraction was filtered through a $0.2 \mu \mathrm{m}$ pore size Supor-200 $25 \mathrm{~mm}$ filter (PALL Corporation), the filter transferred to a sterile tube, and stored at $-80{ }^{\circ} \mathrm{C}$ until extraction. A schematic overview of the nucleic acid extractions and chemistry measurements are given in Additional file 1: Text $\mathrm{S} 1$.

Water samples were filtered through a $0.7 \mu \mathrm{m}$ pore size glass fiber $25 \mathrm{~mm}$ filter (GF/F filter, Whatman). $\mathrm{PO}_{4}$ ${ }^{3-}, \mathrm{NO}_{2}^{-}$, $+\mathrm{NO}_{3}^{-}$were measured with a DR 5000 HachLange spectrophotometer according to Valderrama JC [31]. $\mathrm{SO}_{4}^{2-}$ was also measured on the Hach-Lange spectrophotometer utilizing the LCK 353 kit (Hach-Lange). $\mathrm{Fe}^{2+}$ and $\mathrm{Fe}^{3+}$ were measured with a SmartSpec 3000 Bio-Rad spectrophotometer according to Dawson MV and Lyle SJ [32]. pH (pHenomenal, VWR pH electrode) and redox potential $\left(\mathrm{Ag}^{0} / \mathrm{AgCl} \mathrm{SI}\right.$ Analytics electrode, Mettler Toledo) were also measured. Frozen water and sediment pore-water samples were subsequently used to measure reduced sulfur compounds (tetrathionate and thiosulfate) by cyanolysis [33] according to Kelly DP, Chambers LA, and Trudinger PA [34]. Sediment organic matter (\% wt) was calculated by heating crucibles in a furnace at $550{ }^{\circ} \mathrm{C}$ for $30 \mathrm{~min}$ (OWF 1200, Carbolite), the crucibles were weighed, dry sediment samples added (dried at $80{ }^{\circ} \mathrm{C}$ for 3 days), weighed again, heated at $550{ }^{\circ} \mathrm{C}$ for $4 \mathrm{~h}$, and finally weighed to determine the percentage organic matter. The rate of organic matter degradation was estimated by dividing the sediment percentage organic matter by the amount of incubated days. Sediment pore-water samples were centrifuged at $2200 \mathrm{~g}$ for $15 \mathrm{~min}$, the supernatant filtered through a 0.7 $\mu \mathrm{m}$ pore size glass fiber GF/F $25 \mathrm{~mm}$ filter, and homogenized before being analyzed as described above.

\section{DNA and RNA extraction, sequencing, and bioinformatic analysis}

DNA was extracted from frozen water phase filters according to Boström KH, Simu K, Hagström $\AA$, and Riemann L [35] and stored at $-20{ }^{\circ} \mathrm{C}$ until Illumina library preparation. DNA and RNA extractions from homogenized sediment samples were carried out using the PowerMax Soil DNA and PowerSoil RNA kits (MO BIO Laboratories), respectively. RNA samples were DNase treated twice using the Turbo DNA-free kit (Ambion). After DNase treatment, rRNA was removed using the Ribominus Transcriptome Isolation Kit (Yeast and Bacteria version; Invitrogen Life Technologies). DNA and RNA concentrations were measured using a NanoDrop 2000 and a Qubit 2.0.

The 16S rRNA Illumina library was prepared using PCR primers 341f and 805r [36] and a modified PCR program by Hugerth LW, Wefer HA, Lundin S, Jakobsson HE, Lindberg M, Rodin S, Engstrand L, and Andersson AF [37]. PCR program modification and the processes of adding Illumina adapters and indexes were conducted according to Lindh MV, Figueroa D, Sjöstedt J, Baltar F, Lundin D, Andersson A, Legrand C, and Pinhassi J [38]. Samples were sequenced at Science for Life Laboratory (SciLifeLab), Stockholm using the Illumina MiSeq platform. Most water samples were sequenced with $2 \times 201$ bp pair-ends while sediment samples (and the remaining water samples at time point day 12) were sequenced with $2 \times 301$ bp pair-ends. The $16 \mathrm{~S}$ rRNA gene sequence data were analyzed and sequences clustered into OTUs (97\% similarity) according to UPARSE pipeline [39], as described on the BILS website for using UPARSE on the UPPMAX cluster (available with all scripts at: https://wiki.bils.se/wiki/ Running_the_Uparse_pipeline_at_the_UPPMAX_cluster). After merging of pair-ends and quality filtering, the sediment samples had an average sequence count of 56,271 reads ( $\min 26,712 ; \max 376,267$ ) while the water samples had an average sequence count of 40,335 reads ( $\min 1118$; $\max 83,223$ ). Two water samples, oxic field and one anoxic-to-oxic replicate at the end of the experiment were removed due to a final sequence count below 1000. OTUs were taxonomically annotated with a 95\% sequence identity threshold against the SSU Ref NR 99 v119 SILVA database [40]. The final sequence data was analyzed using Explicet [41]. Rarefraction curves of reads and OTUs were created with the vegan package in $\mathrm{R}$ (reads were subsampled to the lowest sample size). Phylogenetic analysis was conducted by ClustalW sequence alignment and construction of maximum-likelihood trees using MEGA 6 and $7[42,43]$. Habitat specialization was calculated for water samples and their respective sediment samples (field and sliced at the end of the experiment after 21 days) according to Pandit SN, Kolasa J, and Cottenie K [44] using Levin's niche width (B) index:

$$
B=1 / \sum_{i=1}^{N} p_{i j}^{2}
$$

where pij is the proportion of OTU $j$ in the sample $i$ and $N$ is the number of samples. OTUs with high $B$ are classified as habitat generalists and are evenly distributed along a wide range of habitats. In contrast, OTUs with a low B are considered habitat specialists and are unevenly distributed among sampling sites. An average niche width was calculated for each sample, to investigate differences in average niche between treatments. A full list 
of reads obtained from the sequencing facility after merging and quality trimming as well as the clustered OTUs is given in Additional file 2: Table S1.

Extracted community DNA from the end of the oxicto-anoxic $(n=2)$, intermediate-to-oxic $(n=2)$, and anoxic-to-oxic sediment $(n=2)$ experiments were sequenced at SciLifeLab, Stockholm using Illumina MiSeq pair-ends $2 \times 301$ bp (average 7.8 million read pairs per sample). Metagenomic samples were analyzed according the SciLife's Metagenomic Assembly Workshop 2014 (available with all scripts at: http://2014-5-metagenomics-workshop.readthedocs.io/en/latest/assembly/). In detail, Illumina universal adapter and low quality sequences after the adapter were cut from reads using default settings of cutadapt 1.8.0 [45] and then were quality trimmed using sickle 1.210 with default settings. After adapter removal and trimming, approximately $98 \%$ of reads remained with an average length of $155 \mathrm{bp} .16 \mathrm{~S}$ and $18 \mathrm{~S}$ sequences were extracted with SortMeRNA v2.1 [46], and the SILVA SU Ref v 128 database [40] while sequences below $100 \mathrm{bp}$ were removed using fastx_clipper in the FASTX-toolkit. The $16 \mathrm{~S}$ and $18 \mathrm{~S}$ sequences were then clustered for OTUs, reads mapped, and results analyzed in the same manner as the 16S rRNA gene amplicon data. Assembly of the metagenomic data was carried out with a kmer size of 31,41,51,61, 71, and 81 using Ray 2.3.1 [47]. Due to insufficient sequence coverage, only a kmer size of 31 was used and after assembly there was on average 3.4 million contigs with an average length of $193 \mathrm{bp}$ and maximum 14,744 bp. The assembly was annotated using the PROKKA pipeline [48], in which genes were annotated against the UniprotKB/ Swiss-Prot database for functional genes and reference taxonomical organisms. Reads were mapped onto the assemblies using samtools 1.1 [49] and Bowtie2 2.2.3 [50] in conjunction with Picard tools 1.77 (Broad Institute). On average, $35 \%$ of the reads were mapped back onto the assemblies and the counts per gene per was then calculated using BEDTools 2.23 [51]. The final counts were normalized and expressed as counts per million reads (CPM; i.e., relative proportion $\times 1,000,000)$. A full list of reads obtained from the sequencing facility after adapter and quality trimming, the amount of contigs, and their length with N50 values is available in Additional file 2: Table S1.

In total, 11 DNase treated and rRNA depleted RNA sediment samples from the end of the experiment were sequenced: oxic-to-anoxic $(n=2)$, intermediate-to-oxic $(n=2)$, intermediate-to-anoxic $(n=2)$, anoxic-to-oxic $(n=2)$, oxic control $(n=1)$, and anoxic control $(n=2)$. The samples were sequenced at SciLifeLab, Stockholm using Illumina HiSeq pair-ends $2 \times 126$ bp. Illumina universal adapters and low quality sequences following the adapter sequence were cut from reads using SeqPrep with default settings. Sequences were then quality trimmed using Trimmomatic 0.32 with settings LEADING:5 TRAILING:5 MINLEN:36 [52]. This resulted in an average of 19 million read pairs per sample. Due to insufficient sequence coverage of the metagenomic samples, a de novo assembly was chosen for the RNA data. De novo assembly was conducted using Trinity with default settings [53] producing 185,092 contigs of average length 389 bp and maximum length 17,997 bp. After assembly, the Trinotate pipeline was followed (available with all scripts at: https://trinotate.github.io/). The assembly was annotated with BLASTX and BLASTP using the UniProtKB/Swiss-Prot and PFAM databases followed by mapping RNA transcripts and differential expression analysis. rRNA sequences were identified with RNAmmer 1.2. Reads were mapped back onto the assembly using RSEM [54] in conjunction with samtools 1.1 [49] and Bowtie2 2.2.3 [50]. Differential expression was calculated using the package edgeR [55] in the R software suit Bioconductor 3.2. The annotation and differential expression data was loaded into a SQLite Trinotate 2.0.2 database file and was exported as matrix tables. The final differential expression matrix containing all samples was used to cluster significantly expressed RNA transcripts using Euclidean distance clustering with a $p<0.001$ and minimum fold change of four. Annotation of significantly expressed transcripts against the PFAM database was manually compared to that of UniProtKB/Swiss-Prot and showed overall similar results. As more RNA transcripts could be annotated with UniProtKB/Swiss-Prot only annotations from that database are reported. Count values are expressed as trimmed mean of $M$ values (TMM) normalized Fragments Per Kilobase Million (FPKM) units. The reference organisms in the UniprotKB database linked to annotated genes were used to infer the active microbial community composition (expressed as proportion (\%) of FPKM). For significantly expressed RNA transcripts, from edgeR analysis, annotated against UniProtKB/Swiss-Prot, the Uniprot IDs with similar names were merged. The Uniprot IDs that could then be linked to a KEGG Orthology (KO) identifier were merged based on KO name (709 UniProt IDs could be linked). The remaining Uniprot IDs with at least 100 FPKM for any sample were merged by gene name (yielding a total of 157 statistically significant genes). A full list of reads obtained from the sequencing facility and the amount of contigs and their length with N50 values is available in Additional file 2: Table S1. To link the significant genes to a taxonomic affiliation, RNA transcript sequences were annotated using BLAST with five hits against the UniProtKB/ Swiss-Prot database. The top hit reference organism available in the UniProtKB/Swiss-Prot database was used in conjunction with the FPKM values for each sample to calculate proportion of taxonomic affiliation, while the 
remaining hits were used to interpret the data in greater detail.

All samples were sequenced at Science for Life Laboratory, Stockholm using either the Illumina MiSeq or HiSeq platforms. A full list of reads for the various sequencing programs is given in Additional file 2: Table S1. The nucleic acid sequences have the NCBI BioProject accession number: PRJNA322450.

\section{Results}

\section{Chemical fluxes in the water phase and sediments}

Upon oxygenation of anoxic sediments, a $\sim 0.5$-cm light brown surface layer developed (Fig. 1b, d), which indicated that reduced iron had oxidized and iron sulfides no longer colored the sediment black. The anoxic control water phase phosphate $\left(\mathrm{PO}_{4}^{3-}\right)$ concentration increased from $13.1 \pm 0.2 \mu \mathrm{M}$ on day 0 to $26.8 \pm 1.3 \mu \mathrm{M}$ on day 20 (number of replicates $(n)=2, \mathrm{SD}=1$ ) compared to a decrease over the incubation time in all the other cores (Fig. 1e and details in Additional file 3: Table S2). This decrease was likely due to precipitation of $\mathrm{PO}_{4}^{3-}$ coupled to $\mathrm{Fe}^{3+}$ and/or $\mathrm{PO}_{4}^{3-}$ uptake by microorganisms. The $\mathrm{PO}_{4}^{3-}$ concentrations in the surface sediment (top $1 \mathrm{~cm}$ ) pore-water had high variability among cores although the general trend was of a decreasing concentration over time in the anoxic-to-oxic and intermediate-tooxic incubations (Fig. 1f). This variation could potentially be due to $\mathrm{H}_{2} \mathrm{~S}$ interference with the analysis [31] that was also observed in a similar experiment [29]. In contrast, the $\mathrm{PO}_{4}^{3-}$ concentration in the oxic sediment sliced and sampled in the field $(2.4 \pm 0.8 \mu \mathrm{M}, n=3)$ rose to $26.6 \pm 29.1 \mu \mathrm{M}$ in the oxic-to-anoxic incubation after 20 days $(n=2$; Fig. 1f). In the anoxic-to-oxic and intermediate-to-oxic cores these trends were potentially due to $\mathrm{PO}_{4}^{3-}$ uptake by microorganisms and oxidation of $\mathrm{Fe}^{2+}$ to $\mathrm{Fe}^{3+}$ resulting in $\mathrm{Fe}$-bound non-soluble $\mathrm{PO}_{4}^{3-}$ and a $\sim 0.5-\mathrm{cm}$ light brown layer on the sediment surface (Fig. 1b). In the oxic-to-anoxic and intermediateto-anoxic cores these trends were likely due to reduction of $\mathrm{Fe}^{3+}$ causing coupled $\mathrm{PO}_{4}^{3-}$ to become soluble in the pore-water. The opposite trend occurred for the surface sediment $\mathrm{NO}_{2}^{-}+\mathrm{NO}_{3}^{-}$as the concentration decreased over time in the oxic-to-anoxic cores (Fig. 1h). Also in the water phase, the $\mathrm{NO}_{2}^{-}+\mathrm{NO}_{3}^{-}$concentration decreased over time except in the oxic control where it increased from $4.6 \pm 1.0$ on day 0 to $26.0 \pm 7.8 \mu \mathrm{M}$ on day 20 ( $n=2$; Fig. $1 \mathrm{~g})$.

The sediment pore-water sulfate concentration was higher in the oxic control compared to the anoxic control (Fig. 1m), presumably as sulfate reduction in the anoxic sediment converted sulfate to sulfide. This trend was replicated in the anoxic-to-oxic sediment where the sulfate concentration increased as anaerobic sulfate reduction was likely replaced by reduction of oxygen
(Fig. 1m). Inorganic sulfur in the water phase (tetrathionate and thiosulfate) remained low throughout the experiment with no statistically valid differences among the treatments ( $p>0.05$; one-way ANOVA). The thiosulfate concentration was zero in all samples except in the sediment pore-water from the anoxic cores sliced in the field that had $48 \pm 15 \mu \mathrm{m}(n=2$; Additional file 3: Table S2).

The organic matter content in the oxic field sample was $11.7 \pm 1.0 \%(n=3)$ which was lower than the anoxic $(18.4 \pm 0.5 \%, n=3)$ and intermediate (18.5 $\pm 0.6 \%$, $n=2$ ) field sediments (Table 1 ). The oxic and intermediate organic matter content remained stable over the experiment while the anoxic-to-oxic organic matter significantly decreased to $15 \pm 1.4 \%$ (one-way ANOVA, $\mathrm{F}=28.41$, $p<0.01, n=3)$. There was also a statistically significant decrease when the anoxic-to-oxic organic matter decrease was compared to the anoxic control that had $19.0 \pm 0.3 \%$ $(\mathrm{F}=27.48, p<0.05, n=2)$.

\section{Identification of microbial communities}

Rarefraction curves of sequence counts for the $16 \mathrm{~S}$ rRNA gene OTUs showed that most of the microbial diversity had been covered (Additional file 4: Figure S1). A principal component (PCA) analysis based on the relative abundance $16 \mathrm{~S}$ rRNA gene OTUs showed that the oxic sediment samples from both the field and at the end of the experimental incubations were tightly clustered (Fig. 2). In contrast, the samples from the anoxic and intermediate sediment cores were more dispersed after the re-oxygenation treatment. Alpha diversity calculations on all OTUs using Shannon's H index showed a significantly higher diversity in the oxic samples (9.56 $\pm 0.11, n=7)$, compared to intermediate $(8.97 \pm 0.28, n=8)$ and anoxic $(8.75 \pm 0.32, n=7)$ samples (one-way ANOVA; oxic and intermediate $F=22.63$, $p<0.01$, and oxic and anoxic samples $F=26.72$, $p<0.01$; also significantly different with non-parametric Kruskal-Wallis tests $(p<0.01))$. Levin's niche width $(B)$ index was used to analyze the OTU uniformity of distribution between sites, with high values indicating habitat generalists while a low $B$ indicates habitat specialists. All values suggested a majority of generalists although the intermediate sediment samples showed statistically significant higher values $(B=8.11 \pm 0.27, n=9)$ compared to the oxic samples $(7.67 \pm 0.28$, one-way ANOVA, $F=7.85, p<0.05, n=7)$. The anoxic sediment samples had a $B$ value of $7.88 \pm 0.31(n=7)$, and the differences were non-significant with the other groups.

The dominant taxa in the microbial communities from the oxic, intermediate, and anoxic sediments were affiliated with the Delta-, Epsilon-, and Gammaproteobacteria plus Bacteroidetes (Fig. 3). 5952 OTUs (constituting 95.9\% of the total) in the sediment phases at the end of the 


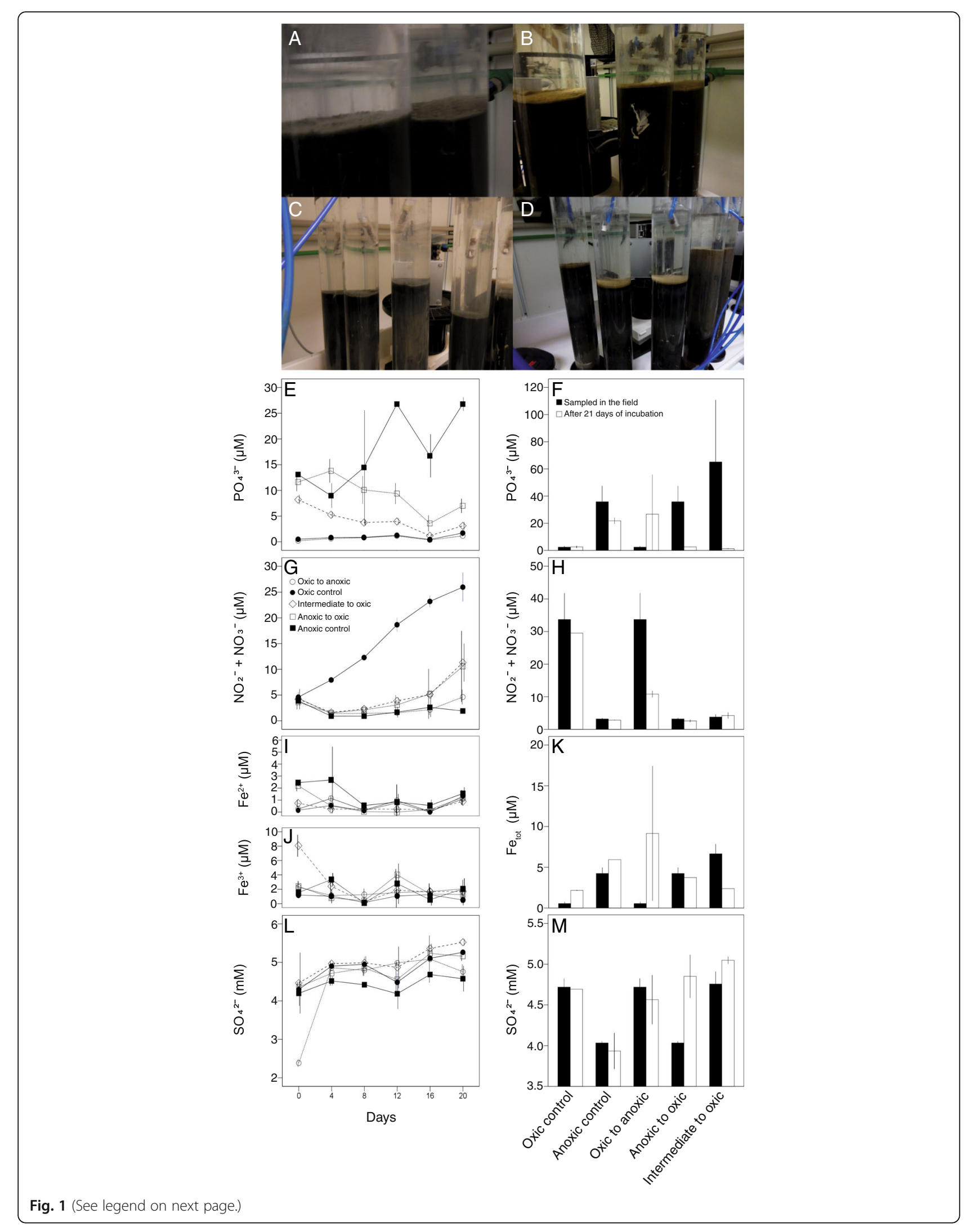


(See figure on previous page.)

Fig. 1 Chemistry data from the incubation experiments. The pictures show a anoxic cores on the first day of incubation; $\mathbf{b}$ anoxic cores turned oxic after 21 days of incubation; $\mathbf{c}$ intermediate cores on the first day of incubation (first three from left side) and anoxic cores on the first day of incubation; and $\mathbf{d}$ intermediate cores turned oxic after 21 days of incubation (first three from left side) and oxic control cores maintained oxic after 21 days of incubation. Measurements of chemistry from the water phase are shown on the left $\mathbf{e} \mathrm{PO}_{4}^{3-}, \mathbf{g ~ N O} \mathrm{NO}_{2}^{-}+\mathrm{NO}_{3}^{-}, \mathbf{i ~ F e}{ }^{2+}, \mathbf{j}$ Fe ${ }^{3+}$, and $\mathbf{~}$ $\mathrm{SO}_{4}^{2-}$ (symbols: black circles, oxic control; black squares, anoxic control; white circles, oxic-to-anoxic; white squares, anoxic-to-oxic; and white diamonds, intermediate-to-oxic); pore-water chemistry from the top 1-cm-sliced sediment are on the right $\mathbf{f} \mathrm{PO}_{4}^{3-}, \mathbf{h ~} \mathrm{NO}_{2}^{-}+\mathrm{NO}_{3}^{-}, \mathbf{k}$ total iron (Fe tot $)$, and $\mathbf{~} \mathrm{SO}_{4}^{2-}$ (black bars denote zero time point measurements from the field and white bars denote measurements at the end of the incubation experiment). All values are averages of triplicates $\pm 1 \mathrm{SD}$, except water and sediment anoxic-to-oxic $(n=2)$ and sediment anoxic-to-oxic $(n=2)$

experiment were relatively stable compared to the field sediments (i.e., changed $<0.1 \%$ in relative abundance). In contrast, more than a $0.1 \%$ increase or decrease in relative abundance of OTUs between the field sediments and the end of the incubations was recorded for 246 OTUs. These changing OTUs represented $47-61 \%$ reads in the initially anoxic sediment, $52-57 \%$ in the intermediate, and 22$25 \%$ in the initially oxic sediment. The changing OTUs primarily belonged to the Sulfurimonas and Sulfurovum genera (Epsilonproteobacteria), but also included, e.g., Desulfobacula, Spirochaeta, and unclassified OTUs (Additional file 5: Figure S2). Consistent with the tightly clustered oxic samples in the PCA (Fig. 2), the relative abundance of the dominant OTUs in the cores from the oxic field samples and after incubations had $\leq 2$-fold difference between all the treatments. These dominant populations included OTUs affiliated with the genera Desulfobulbus, Nitrosomonadaceae, Anaerolineaceae, and Gemmatimonadaceae (Additional file 5: Figure S2 and Additional file 6: Data S1). In the sediment cores from the intermediate site, there was a stronger microbial community shift compared to the oxic cores, with Sulfurimonaslike OTUs increasing from $<1 \%$ in the field samples to a relative abundance of 14.4 and $8.4 \%$ in the intermediateto-oxic and intermediate-to-anoxic cores, respectively (Fig. 3 and Additional file 6: Data S1). Dominant individual Sulfurimonas-like OTUs in the intermediate-tooxic cores increased up to 374-fold (Additional file 6: Data S1). In addition, Sulfurovum-like OTUs increased from $<1 \%$ in the field to a relative abundance of 2.2 and $4.8 \%$ in the intermediate-to-oxic and intermediate-toanoxic cores, respectively (Fig. 3), with one dominant Sulfurovum-like OTU in the intermediate-to-anoxic

Table 1 Organic matter (\%) determined by loss on ignition, on sediment sampled in the field and after 21 days of incubation in darkness after either turned/maintained anoxic/oxic. All values are averages of triplicates $(S D=1)$ except intermediate field, oxic control, and anoxic control (all $n=2$ )

\begin{tabular}{llll}
\hline Sampling site & Field & Turned/kept anoxic & Turned/kept oxic \\
\hline Long-term oxic & $11.7 \pm 1.0$ & $12.5 \pm 0.4$ & $13.1 \pm 0.1$ \\
Intermediate zone & $18.5 \pm 0.6$ & $18.1 \pm 1.4$ & $18.7 \pm 0.4$ \\
Long-term anoxic & $18.4 \pm 0.5$ & $19.0 \pm 0.3$ & $15.0 \pm 1.4$ \\
\hline
\end{tabular}

increasing 365-fold (Additional file 6: Data S1). In the sediment cores from the anoxic site, the relative abundance of Sulfurimonas-like OTUs increased from $4.5 \%$ in the anoxic field sample to $18.4 \%$ in the anoxic control and $13.8 \%$ in the anoxic-to-oxic cores (Fig. 3). Dominant single Sulfurimonas-like OTUs increased up to 414-fold in the anoxic control and up to 565-fold in the anoxic-to-oxic sediment (Additional file 6: Data S1). In contrast, the Sulfurovum-like OTUs decreased from $0.4 \%$ in the field samples to $0.2 \%$ in the anoxic control while increasing strongly to $19.0 \%$ in the anoxic-to-oxic treatment (Fig. 3 and Additional file 6: Data S1). The additional experiment conducted during May 2014 showed similar results regarding Sulfurimonas- and Sulfurovum-like OTUs when exposed to oxygen or maintained anoxic (Additional file 7: Figure S3).

Extracted 16S rRNA gene sequences from the metagenomic dataset at the end of the incubation showed a

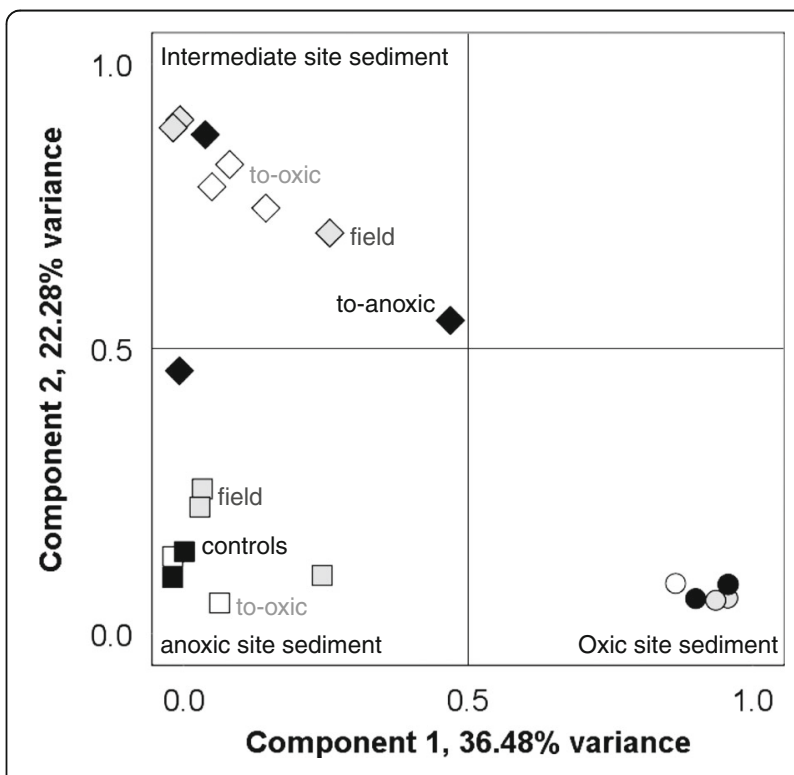

Fig. 2 Principal component analysis of the OTU communities in the top 1-cm sediment layer. Symbols: gray circles, oxic field; black circles, oxic control; white circles, oxic-to-anoxic; gray squares, anoxic field; black squarse, anoxic control; white squares, anoxic-to-oxic; gray diamonds, intermediate field; white diamonds, intermediate-to-oxic; and black diamonds, intermediate-to-anoxic 


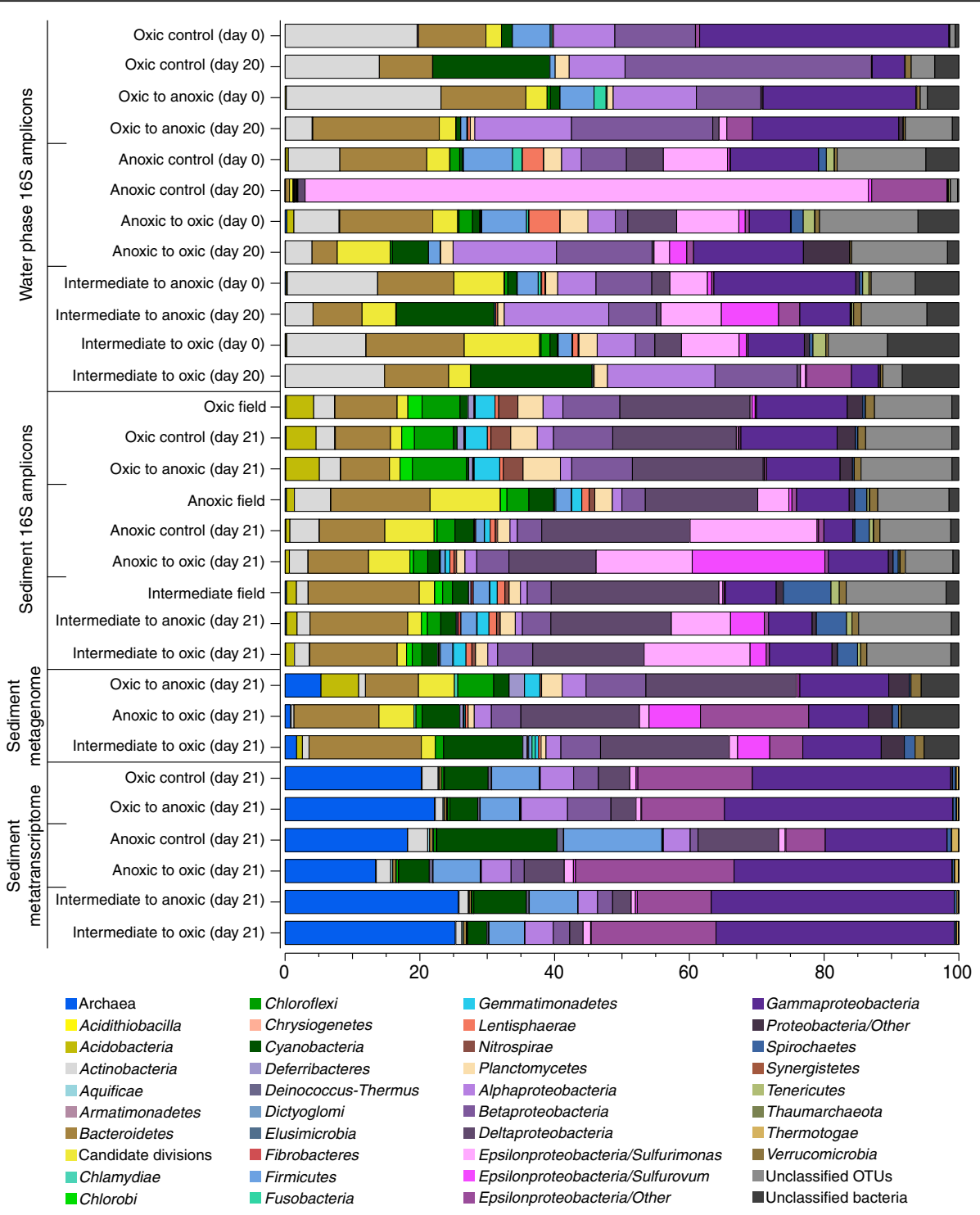

Fig. 3 Stacked bar graphs of microbial community composition from the start and the end of the incubation experiment. The partial 165 rRNA gene amplicons show relative abundance (\%) of counts. Taxonomic affiliation was linked to the metagenome by extracting 165 rRNA gene sequences from the metagenome dataset (relative abundance (\%) of counts is shown). The community composition identified based on the metatranscriptome was derived from the taxonomy affiliated with annotated genes in the metatranscriptomic dataset (proportion (\%) of FPKM). The Proteobacteria are divided into classes and Epsilonproteobacteria has been further divided into Sulfurimonas, Sulfurovum, and other Epsilonproteobacteria

higher relative abundance of archaea in the sediment surface (up to $5 \%$ compared to $0.2 \%$ in the $16 \mathrm{~S}$ amplicon data), possibly due to the primers used for PCR selecting against archaea [37]. The annotated metatranscriptomic dataset showed that archaea were active in the sediment at the end of the incubation and were represented up to $26 \%$ of the annotated data (proportion (\%) of FPKM; Fig. 3). Sulfurimonas-like and Sulfurovum-like OTUs were present in the metagenomic dataset with the highest abundance in the anoxic-to-oxic sediment with 7.6 and $16.1 \%$, respectively. However, these two Epsilonproteobacteria genera did not represent more than $1.4 \%$ in the metatranscriptome data. Instead, Gammaproteobacteria in the sediment had a proportion up to $36 \%$ in the metatranscriptome data at the end of the experiment (Fig. 3).

To investigate changes in microbial community composition due to chemical fluxes from the sediment surface, we also analyzed OTU data in the water phase of the incubated sediment cores. Microbial communities dominant in the water phase consisted of Actinobacteria (Fig. 3) (which is typical for the Baltic Sea [56]), with abundant OTUs primarily belonging to the orders Acidimicrobiales, Corynebacteriales, and Frankiales (Additional file 6: Data S1). Other dominant groups in the water phase 
were Alpha-, Beta-, Epsilon-, Gammaproteobacteria, and Bacteroidetes, along with unclassified OTUs (Fig. 3). In comparison to the sediment community, the water phase contained significantly higher relative abundance of Alphaproteobacteria (one-way ANOVA, $F=27.9$, $p<0.01)$ and lower numbers of Deltaproteobacteria (one-way ANOVA, $F=465.9, p<0.01$ ). In the water phase there was a decreased relative abundance of OTUs affiliated with the Actinobacteria in the oxic-toanoxic (22.5 to $3.9 \%)$ and intermediate-to-anoxic (13.0 to 4.0\%; Fig. 3 and Additional file 6: Data S1). In contrast, an increase was observed in the Cyanobacteria (1.3 to $14.1 \%$ ), Alphaproteobacteria (5.5 to $15.1 \%$ ), and Sulfurovum-like OTUs (0.6 to 8.2\%) (Fig. 3 and Additional file 6: Data S1). The relative abundance of Sulfurimonas-like OTUs strongly increased from 9.4 to $84.2 \%$ in the anoxic control water phase (Fig. 3). A decrease in Bacteroidetes OTUs (13.7 to 3.7\%), order Clostridiales (class Firmicutes, 4.9 to 0.5\%), and Lentisphaerae (4.5 to $0.1 \%$ ) occurred in the anoxic-to-oxic water phase (Fig. 3 and Additional file 6: Data S1).

\section{Correlations between microbial populations (OTUs) and chemical data}

At the level of major taxa, the Actinobacteria, Alpha-, and Betaproteobacteria in the water phase were negatively correlated with $\mathrm{PO}_{4}^{3-}(p<0.01 ; r=-0.42,-0.37$, and -0.44 , respectively; Additional file 8: Table S3). Cyanobacteria and Betaproteobacteria in the water phase positively correlated with $\mathrm{NO}_{2}^{-}+\mathrm{NO}_{3}^{-}$while Cyanobacteria also had a positive correlation to $\mathrm{SO}_{4}^{2-}$ in the water phase $(p<0.05$; Pearson correlations $r=-0.42,-0.37$, and -0.44 , respectively).

In contrast to the water phase, the majority of the major taxa level in the sediment correlated with $\mathrm{NO}_{2}^{-}+\mathrm{NO}_{3}^{-}$(Additional file 8: Table S3). Acidobacteria, Chlorobi, Chloroflexi, Deferribacteres, Gemmatimonadetes, Nitrospirae, Planctomycetes, and Verrucomicrobia all correlated positively with $\mathrm{NO}_{2}^{-}+\mathrm{NO}_{3}^{-}(r=0.49$ to $0.82, p<0.05)$. Groups that correlated negatively included Bacteroidetes, Parcubacteria (OD1), Omnitrophica (OP3), Firmicutes, Lenthisphaerae, and Spirochaetae $(r=-0.44$ to $-0.63, p<0.05$ ). Several of these phyla also positively correlated with $\mathrm{PO}_{4}^{3-}$ (data shown in Additional file 8: Table S3) except Proteobacteria that negatively correlated $(r=-0.66, p<0.01)$. Correlations with $\mathrm{SO}_{4}^{2-}$ were all negative and included the phyla of Actinobacteria, Latescibacteria (WS3), and Candidate division TA06 $(r=-0.50$ to $0.68, p<0.05)$.

The Sulfurimonas-like OTUs in the water phase had a significant positive correlation with $\mathrm{PO}_{4}^{3-}(p<0.01$; $r=0.75)$ while these OTUs in the water phase and sediments had a weak negative correlation to $\mathrm{NO}_{2}^{-}+\mathrm{NO}_{3}^{-}$ $(p<0.05 ; r=-0.28$ and -0.55 , respectively; Additional file 8: Table S3).

\section{Metagenomic analysis of metabolic potential in the sediments}

Sequence assembly approaches of anoxic-to-oxic, intermediate-to-oxic, and oxic-to-anoxic sediment samples yielded on average 50,750 DNA coding sequences of which 6874 were annotated against the UniprotKB/ Swiss-Prot database, giving $\sim 14 \%$ of known and $\sim 86 \%$ hypothetical genes. Similar values have been reported previously in global marine metagenomic sequencing of deep water [57]. Metagenomic gene counts have previously been observed to be a useful tool to estimate the importance of chemical processes in the environment [58].

The annotation against the KEGG database of metagenomic functional genes, also present in the metatranscriptome (see below), revealed nitrification (ammonia oxidation) presence in the oxic-to-anoxic, intermediateto-oxic, and anoxic-to-oxic sediment (counts per million reads $(\mathrm{CPM}): 53 \pm 29,30 \pm 8$, and $198 \pm 92$, respectively, $n=2$ for each treatment, $\mathrm{SD}=1$; Additional file 9: Data S2). Genes suggested to code for dissimilatory nitrate reduction were present in all samples (CPM $81 \pm 47,89 \pm 70$, and $137 \pm 47$ ) while sequences identified as assimilatory nitrate reduction genes were low in all samples (CPM $4 \pm 6,10 \pm 14$, and $68 \pm 78)$. Genes for nitrogen fixation were only found in the anoxic-tooxic sediment (CPM $0 \pm 0,0 \pm 0$, and $56 \pm 79)$. In addition, sequences for genes attributed to dissimilatory sulfate reduction were more abundant in the anoxic-to-oxic sediment (CPM $242 \pm 88,226 \pm 77$, and $542 \pm 11$ ), while the amount of sequences for genes attributed to assimilatory sulfate reduction was highest in the intermediate-to-oxic sediment (CPM $263 \pm 94$, $809 \pm 163$, and $502 \pm 148$ ). Sequences for genes attributed to thiosulfate oxidation (coding for the Sox complex) was present in low abundance in all sediments (CPM $12 \pm 6$, $5 \pm 7,28 \pm 32$ ). Methane oxidation genes from formaldehyde assimilation were present in all treatments with the most sequences in the anoxic-to-oxic sediment (CPM $65 \pm 12,101 \pm 31$, and $228 \pm 144$ ).

\section{Metatranscriptomics of metabolic functions in the sediments}

The de novo assembly of RNA sequences yielded 204,997 transcripts of which 57,386 could be annotated against the UniprotKB/Swiss-Prot (Additional file 9: Data S2) and PFAM reference databases (the two databases gave similar findings and therefore, only results from the UniprotKB/Swiss-Prot are presented hereafter). In the oxic sediments (oxic control: $4938 \pm 0$ and oxicto-anoxic: $6272 \pm 176$ genes), fewer genes were expressed than in the intermediate-to-oxic/to-anoxic 
(7771 \pm 375 and $7643 \pm 303$ genes, respectively) and anoxic control/to-oxic sediments (7859 \pm 414 and $8274 \pm 319$ genes, respectively; Additional file 9: Data S2). RNA transcripts with significantly different FPKM counts according to edgeR analysis are presented in Additional file 9: Data S2 (UniprotKB/Swiss-Prot).

Several of the most abundant known genes in the RNA transcripts were associated with inorganic sulfur transformations indicating activity of oxic and anoxic sulfur cycling in the different treatments (Fig. 4). RNA transcripts annotated for aerobic sulfide oxidation to sulfate were higher in the anoxic-to-oxic and intermediateto-oxic cores compared to the anoxic controls or intermediate cores turned anoxic. These included genes for oxidizing sulfide to sulfur, such as sulfide:quinone oxidoreductase $(s q r)$, sulfide dehydrogenase $(f c c B)$, and dissimilatory sulfite reductase $(d s r A)$ that can act in reverse [59]. Spearman correlations of genes and chemistry data showed a significant negative correlation between sqr and sulfate concentration $(r=0.68, p<0.05$; Additional file 10: Table S4). In addition, heterodisulfide reductase $(h d r A)$, used in both methanogenesis [60] and zero-valent sulfur oxidation [61], were present in all cores from the different treatments (Additional file 9: Data S2). Finally, RNA transcripts for sulfate adenylyltransferase (sat) that is suggested to be used in reverse to oxidize sulfite to sulfate [62] were also present in all cores from all treatments (Additional file 9: Data S2). In the UniprotKB/Swiss-Prot database, these RNA transcripts (Additional file 11: Data S3) were ascribed to Acidithiobacillus/Aquifex (sqr) and Gammaproteobacteria ( $f c c B$ and $d s r A$ ). On the species level, $f c c B$ and $d s r A$ were ascribed to the sulfide oxidizer Allochromatium vinosum (the Chromatiaceae family was present in the 16S rRNA gene data).

In the anoxic control, RNA transcripts annotated as sulfite reductase $(d s v A)$ acting in anaerobic dissimilatory sulfate reduction were higher (FPKM 128 and 192 FPKM for each anoxic control replicate) compared to all other treatments that had FPKM values below 80. These transcripts were ascribed to the genus Desulfovibrio (e.g., species Desulfovibrio vulgaris) that was also present in the 16S rRNA gene dataset (Additional file 6: Data S1). Finally, tetrathionate reductase RNA transcript $(\operatorname{tr} B)$ encoding anaerobic reduction of tetrathionate $\left(\mathrm{S}_{4} \mathrm{O}_{6}^{2-}\right)$ to thiosulfate $\left(\mathrm{S}_{2} \mathrm{O}_{3}^{2-}\right)$ [63] was higher in anoxic-to-oxic (156 to 198 FPKM) and intermediate-to-oxic (217 to 382 FPKM) compared to the anoxic control and intermediate-to-anoxic that had FPKM values below 60 and 110 , respectively.

RNA transcripts coding for organic sulfur compound cycling by anaerobic dimethyl sulfoxide (DMSO) reductase $(d m s A)$ that converts DMSO to dimethyl sulfide (DMS) were higher in the anoxic-to-oxic (1640 to
1993 FPKM) and intermediate-to-oxic treatments (2060 to 2795 FPKM) compared to the anoxic control and intermediate-to-anoxic with FPKM values below 400 and 1250 FPKM, respectively. In addition, transcript counts for the reverse process of anaerobic DMS oxidation back to DMSO by dimethyl sulfide dehydrogenase $(d d h A B)$ were also higher under the same conditions (Additional file 9: Data S2). The genes $t \operatorname{tr} B, d m s A$, and $d d h A B$ all had a positive significant correlation with sulfate concentrations $(r=0.72-0.78, p<0.05$; Additional file 10: Table S4). The RNA transcripts for $d m s A$ were affiliated with the class Halobacteria belonging to the Euryarchaeota phylum, while those for $\operatorname{ddh} A B$ were affiliated with the Alphaproteobacteria family Rhodobacterales (Additional file 11: Data S3). Both of these lineages were present in the $16 \mathrm{~S}$ rRNA gene dataset (Additional file 6: Data S1).

RNA transcripts for genes mediating methane oxidation ( $p m o A 1 A 2$ and pmoB1B2 encoding methane monooxygenase) were higher in anoxic-to-oxic (2232 to 3542 FPKM) compared to the anoxic control $(<220$ FPKM) as well as in the oxic control (720 for pmoA1A2, and 564 for $p m o B 1 B 2 ; n=1$ ) compared to the oxic-to-anoxic treatment that had FPKM values below 40 (Fig. 4). In contrast, RNA transcripts for genes coding for methane oxidation were not higher in the intermediate-to-oxic treatments (Additional file 9: Data S2). RNA transcripts for $p m o A 1 A 2$ and pmoB1B2 had a significant positive correlation with redox potential (i.e., high redox had more of these RNA transcripts; $r=0.83, p<0.01$; Additional file 10: Table S4) and were ascribed to the Gammaproteobacteria reference organism Methylococcus capsulatus (Additional file 11: Data S3) that was present in the 16S rRNA gene dataset (Additional file 6: Data S1). RNA transcripts coding for methanogenesis (acs $A$, $m t a B$, and $m t b C 2 C 3)$ were higher in the anoxic control (168 to 821 FPKM) compared to the anoxic-tooxic sediment (13 to 194 FPKM). Also, mtaB and $m t b C 2 C 3$ had more RNA transcripts attributed in the intermediate-to-anoxic cores (33 to 206 FPKM) when compared intermediate-to-oxic (2 to 72 FPKM; Fig. 4). The acs $A$ RNA transcripts were affiliated with a wide diversity of bacteria including, e.g., Alpha-, Beta-, Epsilon-, and Gammaproteobacteria (Additional file 11: Data S3). RNA transcripts for $m t a B$ affiliated with the archaeal class Methanomicrobia and Alphaproteobacteria class Rickettsiales, while $m t b C 2 C 3$ affiliated only with Methanomicrobia (Additional file 11: Data S3); both of these classes were present in the $16 \mathrm{~S}$ rRNA gene dataset (Additional file 6: Data S1). RNA transcripts encoding $h d r A$ used during anaerobic methanogenesis [64] were present in all cores for all treatments. 

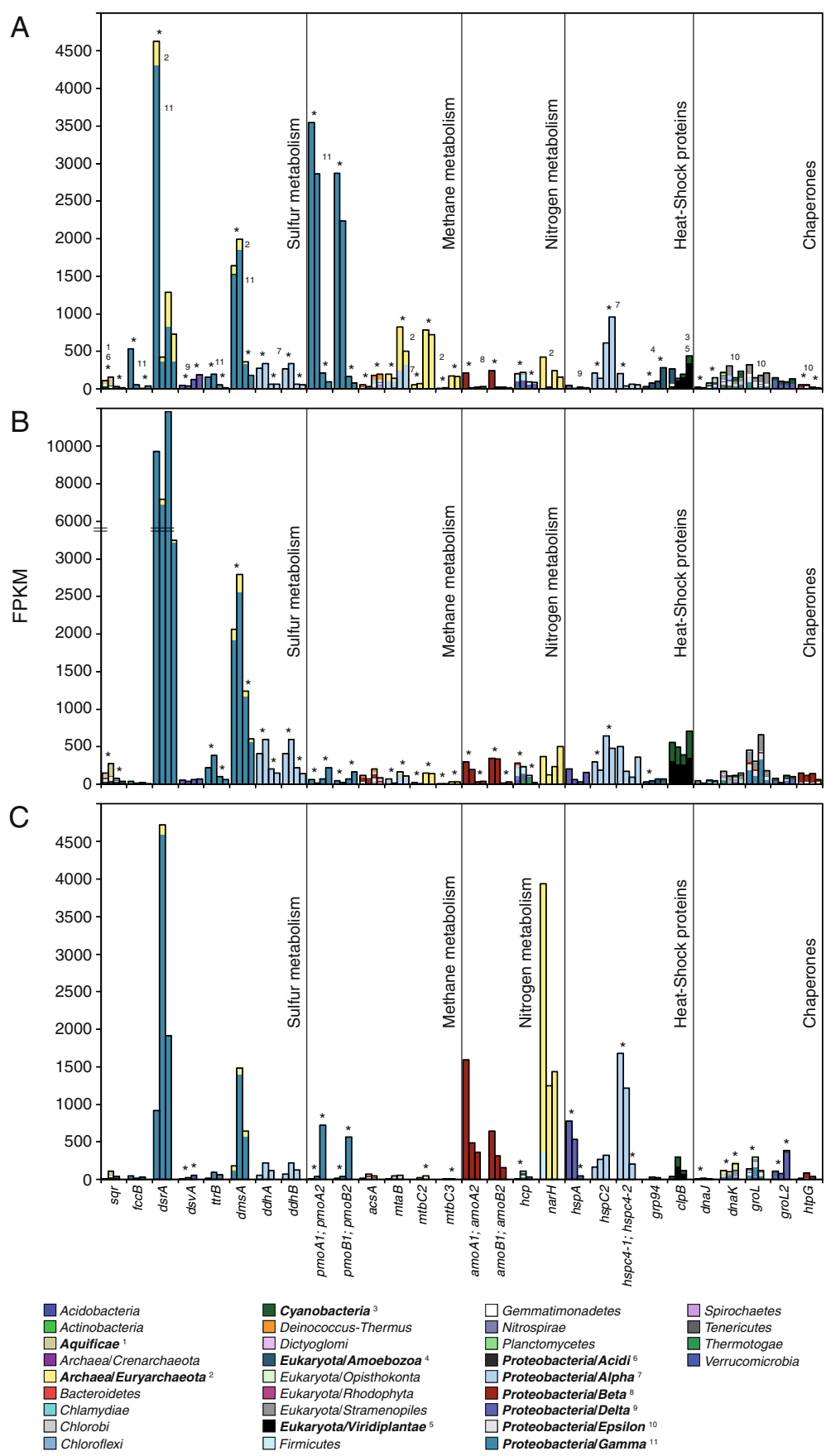

Fig. 4 RNA transcripts of major metabolic processes in the sediments. Selected functional groups of RNA transcripts from the sediment after incubation in darkness for 21 days (RNA transcripts that were $\geq 100$ FPKM in one of the treatments are shown). Functional groups were chosen based on statistical significance from edgeR analysis of the studied chemistry and 16S rRNA gene data. a Anoxic-to-oxic ( $n=2$, two left bars for each gene) and anoxic control ( $n=2$, two right bars for each gene). b Intermediate-to-oxic $(n=2$, left bars) and intermediate-to-anoxic ( $n=2$, right bars). $\mathbf{c}$ Oxic-to-anoxic ( $n=2$, left bars) and oxic control $(n=1$, right bar). Stars denote a fold change of at least 1.5 for the average of the two replicates compared to each replicate of the other shown treatment. All values show TMM normalized FPKM units. The colors denote relative abundance (\% relative to column height) of taxonomic groups for the annotated RNA transcripts (i.e., derived from top hit organism in the UniprotKB/Swiss-Prot database)

RNA transcripts coding for nitrate reductase (narH) were higher in the oxic-to-anoxic cores (1250 to 394. FPKM) compared the oxic control (1436 FPKM). In addition, RNA transcripts coding for narH were found at lower amounts in the other treatments (Fig. 4). RNA transcripts attributed to $n a r H$ also correlated positively with $\mathrm{NO}_{2}^{-}+\mathrm{NO}_{3}^{-}(r=0.68, p<0.05$; Additional file 10: Table S4). These RNA transcripts were mainly affiliated 
with halophilic denitrifying archaeal species belonging to the class Halobacteria (closest available affiliation in UniProt KB: Haloferax mediterranei; Additional file 11: Data S3). Halobacteria were also present in the $16 \mathrm{~S}$ rRNA gene data (Additional file 6: Data S1) and phylogenetic analysis, with reference sequences of Marine group I, II, III, IV, and Haloferax species, indicated that the OTUs aligned with the order Halobacteriales and the 'Deep Sea Hydrothermal Vent Group 6' (DHVEG-6; Additional file 12: Figure S4). These Halobacteria in the sediment might thrive in micro-niches or contain lowsaline species as has been reported previously in sulfur and sulfide rich conditions [65].

In general, there was a low level of RNA transcripts coding for the general stress response in all treatments (Fig. 4). One exception was for the HSP70 family (hspA) that had higher RNA transcripts in the oxic-to-anoxic cores (538 to 778 FPKM) compared to the oxic control (46 FPKM). A second exception was for HSP90 family genes (hspC2/4-1/4-2) that had more RNA transcripts attributed in the oxic-to-anoxic cores (1216 to 1682 FPKM) compared to the oxic control (205 FPKM). The taxonomic affiliations of RNA transcripts coding for general stress were diverse and also included eukaryotes such as Amoebozoa. In addition, the chaperones $d n a K$ and $h t p G$ were assigned to Sulfurimonas and Sulfurovum spp. (Additional file 11: Data S3) that tended to be higher in treatments turned oxic or the oxic control cores.

\section{Discussion}

In this study, we investigated changes in the microbial community composition and metabolic function in longterm oxic and anoxic sediments plus intermediate sediments from a Baltic Sea coastal bay. The tightly clustered microbial communities in the oxic sediment field sample, control cores, and oxic-to-anoxic incubations were likely due to long time exposure to oxygen selecting for obligate aerobes (PCA, Fig. 2). In contrast, microbial communities in the anoxic-to-oxic sediment incubations were slightly less clustered, potentially as facultative anaerobes could adapt to increased oxygen concentrations. The intermediate sediment communities were most widespread compared to other locations, with populations of generalists adapted to the changing oxygen concentration. This suggested that historical oxygen concentrations will affect the microbial response to shifts in oxygen concentrations.

Reduction of sulfate to $\mathrm{H}_{2} \mathrm{~S}$ by sulfate-reducing bacteria is prevalent in Baltic Sea sediments including anoxic sediment rich in labile organic matter [66] and the generated sulfide can be re-oxidized to sulfate in aerobic conditions [67]. Recent molecular phylogenetic and genetic analyses show that many genes coding for sulfur cycling processes occur in anoxic environments. For example, a metagenomic investigation of the waters in the oxygen-minimum zone outside the northern Chilean coast found that genes for both sulfate reduction and sulfide oxidation were present in the anoxic water [68]. Furthermore, with the use of isotope-labeled sulfate and oxygen, cryptic sulfur cycling was observed in anoxic salt march sediments. The results indicate microbial reduction of sulfate to $\mathrm{H}_{2} \mathrm{~S}$ followed by microbial re-oxidation of $\mathrm{H}_{2} \mathrm{~S}$ into intermediary sulfur species and eventually sulfate [69]. Consistent with this data, the anoxic sediment turned oxic compared to cores kept or turned anoxic had increased sulfate in the pore-water (Fig. 1); more RNA transcript numbers for inorganic sulfur oxidation genes (Fig. 4) [62, 70]; and an increase in Sulfurovum-like OTUs (Fig. 3) that contain genes attributed to sulfide oxidation to sulfate [71, 72] suggesting they carried out sulfur oxidation. Considering that sulfur cycling RNA transcripts could not be directly linked to Sulfurovum and instead transcripts attributed to chaperones $d n a K$ and $h t p G$ were linked to this genus (Additional file 11: Data S3), it is possible that the sulfur cycling activity by Sulfurovum had declined after 21 days of incubation. Also consistent with these findings was that compared to the field data Sulfurimonas-like populations increased in cores maintained anoxic, while negatively correlating with the $\mathrm{NO}_{2}^{-}+\mathrm{NO}_{3}^{-}$concentration (Additional file 8: Table S3) suggesting they oxidized sulfide coupled to nitrate reduction. However, RNA transcripts coding for nitrate reductase (narH) mainly aligned with Euryarchaeota. It is possible that a precise taxonomic affiliation cannot be determined for this conserved gene, and it can only be concluded that the microbial community utilized $\mathrm{NO}_{3}^{-}$as a terminal electron acceptor under anaerobic conditions [73]. Taken together, the RNA transcripts coding for sulfur oxidation and reduction reactions and the low concentrations of zero-valent sulfur and reduced sulfur compounds throughout the incubations (Additional file 3: Table S2) suggested that a cryptic cycling of sulfur and sulfur compounds occurred in the sediment. Furthermore, we observed genes used in anaerobic metabolism in the $1 \mathrm{~cm}$ sediment slices turned oxic. This indicated that changes in oxygen conditions in the sediment surface oxic layer (reaching $\sim 1.5 \mathrm{~mm}$ ) affected anaerobic microbial metabolism in the underlying anoxic layer.

As described above, the sulfur cycling related $16 \mathrm{~S}$ rRNA gene amplicons, mRNA transcripts, and chemistry data in conjunction with qualitative observations that the sediment surface turned brown and had a lowered sulfide odor strongly supported that Sulfurovum-like populations were favored in the surface of anoxic-tooxic incubations. This is consistent with the description of this genus that grows via sulfur compound oxidation with the reduction of oxygen or nitrate [74]. These 
populations would potentially act as a $\mathrm{H}_{2} \mathrm{~S}$ oxidation barrier between the oxygenated sediment surface and the deeper anoxic $\mathrm{H}_{2} \mathrm{~S}$ rich sediment and would accelerate removal of $\mathrm{H}_{2} \mathrm{~S}$.

Most methane oxidation occurs in the sediment surface and limits the amount of this potent greenhouse gas to escape from the water column [75]. RNA transcripts coding for methane oxidation were highest in the anoxic-to-oxic and oxic control (Fig. 4). This was likely explained by oxygen reaching anoxic layers below the sediment surface that triggered transcription of these genes. The RNA transcripts encoding pmoAB and $16 \mathrm{~S}$ rRNA data suggested methane oxidation in the anoxicto-oxic and oxic control was mediated by Methylococcales, a microorganism that typically grows in the upper layers of marine sediment [76]. In contrast, methanotrophyrelated RNA transcripts were lower in the intermediateto-oxic sediment compared to the intermediate-to-anoxic. Thus, stored methane had potentially been metabolized during episodic oxygenation events or alternatively, the methanogenic archaea were inhibited during these oxygenation episodes. Irrespective of the precise mechanism, intermediate zones with fluctuating oxygen concentrations may not produce the greenhouse gas methane while an anoxic-to-oxic shift resulted in increased methanotrophy that would consume the methane and halt its escape to the atmosphere. Thus, gene expression analysis indicated an intricate balance between production and consumption of methane in intermittently and permanently anoxic sediments.

It has previously been shown that degradation of experimentally added organic matter to sediments is slower under anoxic compared to oxic conditions [22, 23]. In addition, Hulthe G, Hulth S, and Hall POJ [77] found that old, buried organic matter was more rapidly oxidized upon re-oxygenation of anoxic sediments compared to fresh organic matter in the sediment surface (which was degraded at similar rates both aerobically and anaerobically). A statistically significant decrease in organic matter was observed when the anoxic sediment was turned oxic, but not in the initially anoxic intermediate sediment upon oxygenation (Table 1). Considering that more organic matter is preserved in low oxygen zones [21], here we have shown that the preserved organic matter in the long-term studied anoxic zone was degraded upon oxygenation. In contrast, this was not the case for

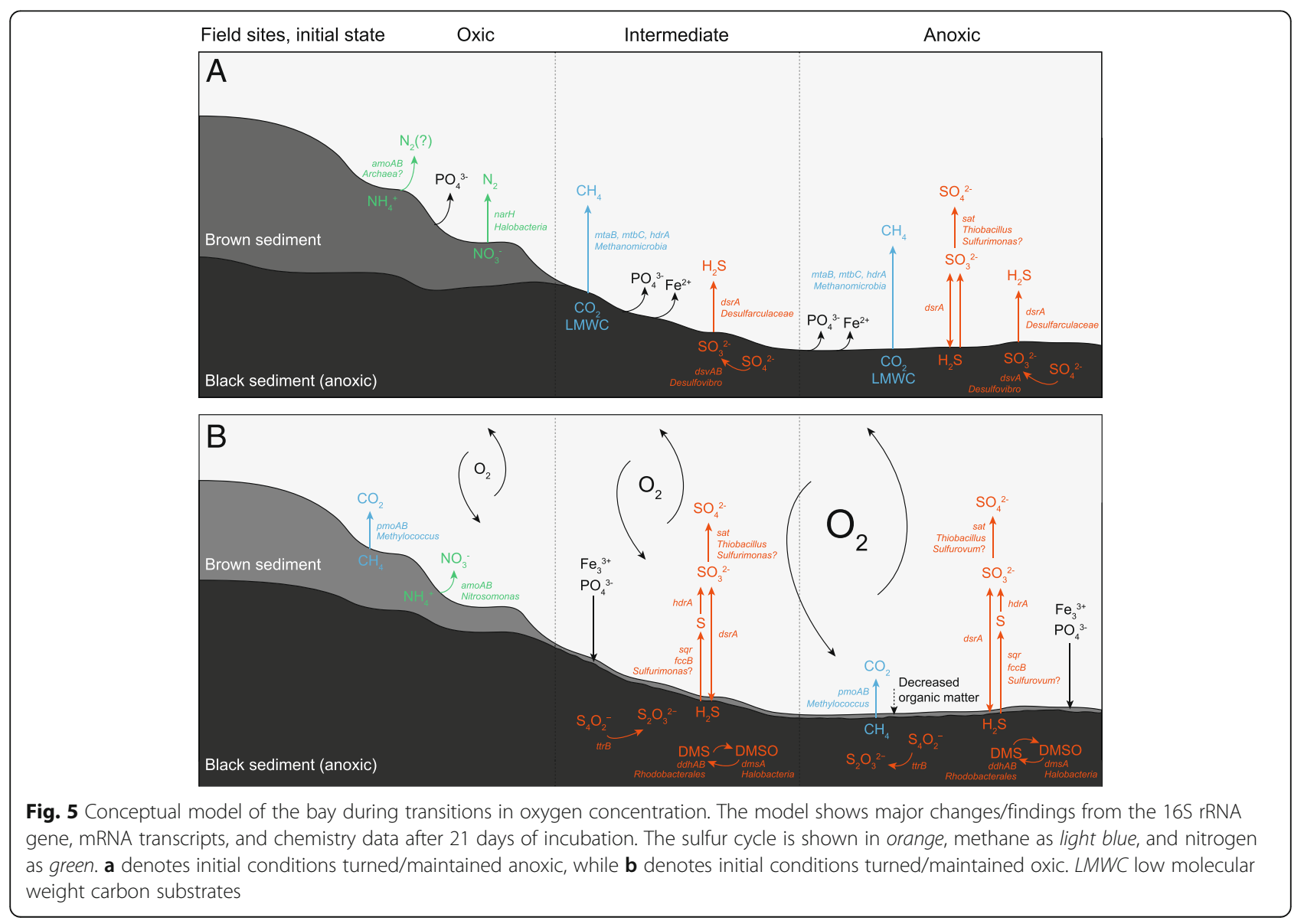


the intermediate area subjected to episodic variations in oxygen concentration where the stored organic matter would likely have been periodically depleted.

\section{Conclusions}

In conclusion, we show for the first time the large changes in microbial populations and genes suggested to code for metabolic processes inflicted by shifts in oxygen levels in coastal oxic, intermediate, and anoxic zones (Fig. 5). In a coastal anoxia dead zone remediation scenario, oxygenation of the sediment surface was followed by an increase in bacterial populations affiliated with the genus Sulfurovum and RNA transcripts attributed to sulfur cycling (such as oxidation of toxic $\mathrm{H}_{2} \mathrm{~S}$ ) that would potentially prevent $\mathrm{H}_{2} \mathrm{~S}$ from ascending into the water column. Additionally, a decrease in methane release was indicated by higher amounts of RNA transcripts attributed to methane oxidation. This was also indicated by lower amounts of RNA transcripts for methanogenesis when compared to the anoxic controls. Oxygenation of anoxic sediment would therefore likely limit the release of this greenhouse gas to the atmosphere. These findings have important implications in the context of proposed remediation strategies for coastal dead zones, such as those found in the Baltic Sea. These strategies include mixing the water column using pump stations, circulating oxygenated water to the sea bottom [78, 79]. One such study was conducted in a fjord on the west coast of Sweden where the re-oxygenated bottom zone showed a decrease in phosphate [80] that would help hypoxic and anoxic coastal zones to recover from eutrophication [81]. Addition of oxygen in conjunction with microbial removal of $\mathrm{H}_{2} \mathrm{~S}$ would help macro-organism communities to reestablish in the surface sediment and benthic zone that was supported by increased hatching of zooplankton eggs in a similar experiment [29]. Additionally, re-oxygenation of the anoxic sediment surface resulted in decreased stored organic matter (Table 1) and it was estimated that it would take approximately 73 days for the anoxic sediment to reach the level of organic matter in the long-term oxic field sediment (without further addition of organic matter from the water column that would likely be oxidized first). These $\sim 2.5$ months may be a crucial time necessary for restoration of coastal dead zones and would potentially require continuous re-oxygenation. Based on the results found in this study, we suggest that remediation efforts of dead zones effectively depend on the microbial community response and that these responses will vary locally/regionally depending on anoxia history. Furthermore, it was shown that re-oxygenation efforts to remediate dead zones could ultimately be facilitated by in situ microbial molecular mechanisms involved in removal of toxic $\mathrm{H}_{2} \mathrm{~S}$ and the potent greenhouse gas methane.

\section{Additional files}

Additional file 1: Text S1. Detailed methodology of field sampling and the sub-sampling procedure. (DOCX $271 \mathrm{~kb}$ )

Additional file 2: Table S1. A full list of reads for the various sequencing programs including before and after merging reads, quality trimming and bioinformatic statistics on the assemblies constructed from the metagenomes and de-novo assembled metatranscriptoms. (DOCX 62 kb)

Additional file 3: Table S2. Chemistry data from the water phase and the sediment collected in the field, during, and at the end of the incubation experiment. All values are averages of triplicates $(S D=1)$ except oxic and anoxic controls $(n=2)$, water and sediment oxic-to-anoxic, and sediment anoxic-to-oxic (both $n=2$ ). All chemistry data in the sediment was measured using the pore-water except organic matter which was measured using the loss on ignition method. (XLSX $16 \mathrm{~kb}$ )

Additional file 4: Figure S1. Rarefraction curves of counts and OTUs for each treatment in the water phase and sediment (counts were subsampled to lowest sample size). Each curve denotes a biological replicate. (PDF $104 \mathrm{~kb}$ )

Additional file 5: Figure S2. Phylogenetic tree showing OTUs derived from the 165 rRNA gene analysis. Included OTUs had a relative abundance higher than $1 \%$ in one or more samples derived from the top 1-cm sediment surface sliced in the field and at the end of the incubation experiment. Sequences downloaded from NCBI GenBank have been marked with a dashed line in the heat map. The tree was rooted with a marine Actinomycete (NCBI accession: AJ866956.1). (PDF 456 kb)

Additional file 6: Data S1. All OTUs and a separate list for the top 10 abundant, annotated against the SILVA database. All values are reported as relative abundances, with triplicates $(S D=1)$ except water and sediment oxic-to-anoxic and sediment anoxic-to-oxic (both $n=2$ ). The second sheet shows the taxonomy results based on extracted $16 \mathrm{~S}$ and $18 \mathrm{~S}$ rRNA gene sequences from the sediment metagenome dataset. (XLSX $1447 \mathrm{~kb}$ )

Additional file 7: Figure S3. 165 rRNA gene sequence data of annotated OTUs in the sediment of an additional oxygen transition experiment. Ten sediment cores from the anoxic site were sampled on the 15 May 2014. During 26 days of incubation, 5 cores were maintained anoxic while the other 5 cores were turned oxic using similar methodology as describe in the main article. The Proteobacteria have been divided into classes, and the Epsilonproteobacteria has been divided into two genus Sulfurimonas and Sulfurovum, and other Epsilonproteobacteria. (PDF $151 \mathrm{~kb}$ )

Additional file 8: Table S3. Pearson correlations of chemistry data and relative abundance of annotated phyla, classes, orders, and the genera Sulfurimonas and Sulfurovum in the water phase and the sediment. The orange shading denotes statistically significant $p$ values at $<0.01\left({ }^{* *}\right)$ and $<0.05\left(^{*}\right)$. The last table shows Spearman correlations of selected genes derived from statistically significant RNA transcripts (as shown in Fig. 4) and sediment chemistry data after 21 days of incubation. (DOCX $159 \mathrm{~kb}$ )

Additional file 9: Data S2. The list shows all results (FPKM), with a following separate list of the significant results, from the UniprotKB/SwissProt database annotation of the de novo metatranscriptomic assemblies ( $n=2$, for each treatment except oxic control: $n=1$ ), SD =1. The second sheet shows the results from annotation of functional genes derived from the metagenome. (XLSX $2747 \mathrm{~kb}$ )

Additional file 10: Table S4. Spearman correlations of statistically significant genes from edgeR (as seen in Fig. 4) derived from the extracted sediment RNA and sediment chemistry measurements after 21 days of incubation. (DOCX $50 \mathrm{~kb}$ )

Additional file 11: Data S3. Reference organisms from the UniProtKB/ Swiss-Prot database tied to the annotation of chosen 'RNA transcriptrelated genes' (top five hits are shown). (XLSX $114 \mathrm{~kb}$ )

Additional file 12: Figure S4. Phylogenetic unrooted maximumlikelihood tree (bootstrapped 100 times) showing archaeal OTUs derived from the 165 rRNA gene analysis compared to reference sequences downloaded from NCBI GenBank that are colored red. The scale bar represents nucleotide substitutions per site (i.e., substitutions divided by sequence length). (PDF $244 \mathrm{~kb}$ ) 


\section{Acknowledgements}

We thank Sabina Arnautovic for excellent technical support in the laboratory. We also thank Susanna Andersson and Stefan Tobiasson in the Linnaeus University Coastal Group for assistance during sampling. The authors acknowledge the support from Science for Life Laboratory and the Nationa Genomics Infrastructure for providing assistance in massive parallel sequencing and computational infrastructure. The computations were performed on resources provided by SNIC through the Uppsala Multidisciplinary Center for Advanced Computational Science (UPPMAX) under Project b2013127.

\section{Funding}

This work was supported by grants from the Linnaeus University to EEMiS and from the Swedish Research Council to J.P. and M.D.

\section{Availability of data and materials}

All data generated or analyzed during this study are included in this published article.

\section{Authors' contributions}

EB designed the study, sampled in the field, conducted laboratory work, analyzed data, and drafted the manuscript. JS assisted in the laboratory and data analysis. JP and MD designed the study, helped to draft and revise the manuscript. All authors read and approved the final manuscript.

\section{Ethics approval and consent to participate}

Not applicable.

\section{Consent for publication}

Not applicable.

\section{Competing interests}

The authors declare that they have no competing interests.

\section{Publisher's Note}

Springer Nature remains neutral with regard to jurisdictional claims in published maps and institutional affiliations.

\section{Author details}

${ }^{1}$ Centre for Ecology and Evolution in Microbial Model Systems (EEMiS), Linnaeus University, Kalmar, Sweden. ${ }^{2}$ Present address: Department of Biology/Aquatic ecology, Lund University, Sölvesgatan 37, 22362 Lund, Sweden. ${ }^{3}$ Present address: Centre for Ocean Life, Institute for Aquatic Resources, Technical University of Denmark, 2900 Charlottenlund, Denmark.

\section{Received: 20 June 2017 Accepted: 18 July 2017}

\section{Published online: 09 August 2017}

\section{References}

1. Schmidtko S, Stramma L, Visbeck M. Decline in global oceanic oxygen content during the past five decades. Nature. 2017;542:335-9.

2. Conley DJ, Carstensen J, Aigars J, Axe P, Bonsdorff E, Eremina T, Haahti BM Humborg C, Jonsson P, Kotta J, et al. Hypoxia is increasing in the coastal zone of the Baltic Sea. Environ Sci Technol. 2011;45:6777-83.

3. Diaz RJ, Rosenberg R. Spreading dead zones and consequences for marine ecosystems. Science. 2008;321:926-9.

4. Emeis KC, Struck U, Leipe T, Pollehne F, Kunzendorf H, Christiansen C, Emeis KC, Struck U, Leipe T, Pollehne F, et al. Changes in the C, N, P burial rates in some Baltic Sea sediments over the last 150 years-relevance to $P$ regeneration rates and the phosphorus cycle. Mar Geol. 2000:167:43-59.

5. Middelburg JJ, Meysman FJR. Burial at sea. Science. 2007;316:1294-5.

6. Burdige DJ. Geochemistry of marine sediments. Princeton: PRINCETON University Press; 2006.

7. Kochling T, Lara-Martin P, Gonzalez-Mazo E, Amils R, Sanz JL. Microbial community composition of anoxic marine sediments in the bay of Cadiz (Spain). Int Microbiol. 2011;14:143-54.

8. Nealson KH. Sediment bacteria: Who's there, what are they doing, and what's new? Annu Rev Earth Planet Sci. 1997;25:403-34.

9. Munn C: Marine microbiology: ecology and applications. Garland Science; 2011.

10. Carstensen J, Andersen JH, Gustafsson BG, Conley DJ. Deoxygenation of the Baltic Sea during the last century. Proc Natl Acad Sci U S A. 2014;111: 5628-33.
11. Kabel K, Moros M, Porsche C, Neumann T, Adolphi F, Andersen TJ, Siegel H, Gerth M, Leipe T, Jansen E, Sinninghe Damste JS. Impact of climate change on the Baltic Sea ecosystem over the past 1,000 years. Nat Clim Chang. 2012:2:871-4.

12. Bagarinao T. Sulfide as an environmental factor and toxicant: tolerance and adaptations in aquatic organisms. Aquat Toxicol. 1992;24:21-62

13. Choi H, Koh HW, Kim H, Chae JC, Park SJ. Microbial community composition in the marine sediments of Jeju Island: next-generation sequencing surveys. J Microbiol Biotechnol. 2016;26:883-90.

14. Edlund A, Hårdeman F, Jansson JK, Sjöling S. Active bacterial community structure along vertical redox gradients in Baltic Sea sediment. Environ Microbiol. 2008;10:2051-63.

15. Ye Q, Wu Y, Zhu Z, Wang X, Li Z, Zhang J. Bacterial diversity in the surface sediments of the hypoxic zone near the Changjiang estuary and in the East China Sea. Microbiol Open. 2016:5:323-39.

16. Straub KL, Benz M, Schink B, Widdel F. Anaerobic, nitrate-dependent microbial oxidation of ferrous iron. Appl Environ Microbiol. 1996:62:1458-60.

17. Takai K, Suzuki M, Nakagawa S, Miyazaki M, Suzuki Y, Inagaki F, Horikoshi K. Sulfurimonas paralvinellae sp. nov., a novel mesophilic, hydrogen- and sulfur-oxidizing chemolithoautotroph within the Epsilonproteobacteria isolated from a deep-sea hydrothermal vent polychaete nest, reclassification of Thiomicrospira denitrificans as Sulfurimonas denitrificans comb. nov. and emended description of the genus Sulfurimonas. Int I Syst Evol Microbiol. 2006;56:1725-33.

18. Burdige DJ. The biogeochemistry of manganese and iron reduction in marine sediments. Earth-Sci Rev. 1993;35:249-84.

19. Jørgensen B. Bacteria and marine biogeochemistry. In: Schulz H, Zabel M, editors. Marine Geochemistry. Berlin Heidelberg: Springer; 2006. p. 169-206.

20. Metzger E, Langlet D, Viollier E, Koron N, Riedel B, Stachowitsch M, Faganeli J, Tharaud M, Geslin E, Jorissen F. Artificially induced migration of redox layers in a coastal sediment from the northern Adriatic. Biogeosciences. 2014;11:2211-24.

21. Koho KA, Nierop KGJ, Moodley L, Middelburg JJ, Pozzato L, Soetaert K, van der Plicht J, Reichart GJ. Microbial bioavailability regulates organic matter preservation in marine sediments. Biogeosciences. 2013;10:1131-41.

22. Kristensen E, Ahmed SI, Devol AH. Aerobic and anaerobic decomposition of organic matter in marine sediment: which is fastest? Limnol Oceanogr. 1995:40:1430-7.

23. Sun M-Y, Aller RC, Lee C, Wakeham SG. Effects of oxygen and redox oscillation on degradation of cell-associated lipids in surficial marine sediments. Kidlington: Elsevier; 2002.

24. Bolhuis H, Stal $\mathrm{L}$. Analysis of bacterial and archaeal diversity in coastal microbial mats using massive parallel 165 rRNA gene tag sequencing. ISME J. 2011:5:1701-12.

25. Wang $Y$, Sheng H-F, He Y, Wu J-Y, Jiang Y-X, Tam NF-Y, Zhou H-W. Comparison of the levels of bacterial diversity in freshwater, intertidal wetland, and marine sediments by using millions of Illumina tags. Appl Environ Microbiol. 2012;78:8264-71.

26. Swan BK, Ehrhardt CJ, Reifel KM, Moreno LI, Valentine DL. Archaeal and bacterial communities respond differently to environmental gradients in anoxic sediments of a california hypersaline lake, the Salton Sea. Appl Environ Microbiol. 2010;76:757-68.

27. Edlund A, Soule T, Sjoling S, Jansson JK. Microbial community structure in polluted Baltic Sea sediments. Environ Microbiol. 2006;8:223-32.

28. Divya B, Parvathi A, Loka Bharathi PA, Nair S. 165 rRNA-based bacterial diversity in the organic-rich sediments underlying oxygen-deficient waters of the eastern Arabian Sea. World J Microbiol Biotechnol. 2011:27:2821-33.

29. Broman E, Brüsin M, Dopson M, Hylander S. Oxygenation of anoxic sediments triggers hatching of zooplankton eggs. Proc R Soc Lond B Biol Sci. 2015;282

30. Feike J, Jurgens K, Hollibaugh JT, Kruger S, Jost G, Labrenz M. Measuring unbiased metatranscriptomics in suboxic waters of the central Baltic Sea using a new in situ fixation system. ISME J. 2012;6:461-70.

31. Valderrama JC. Methods of nutrient analysis. In: Hallegraeff GM, ADaCA, editors. Manual on harmful marine microalgae. Paris: Intergovernmental Oceanographic Commision of UNESCO; 1995. p. 251-68. IOC manuals and guides.

32. Dawson MV, Lyle SJ. Spectrophotometric determination of iron and cobalt with Ferrozine and dithizone. Talanta. 1990;37:1189-91.

33. Sörbo B. A colorimetric method for the determination of thiosulfate. Biochim Biophys Acta. 1957;23:412-6. 
34. Kelly DP, Chambers LA, Trudinger PA. Cyanolysis and spectrophotometric estimation of trithionate in mixture with thiosulfate and tetrathionate. Anal Chem. 1969;41:898-901.

35. Boström KH, Simu K, Hagström $\AA$, Riemann L. Optimization of DNA extraction for quantitative marine bacterioplankton community analysis. Limnol Oceanogr Methods. 2004:2:365-73.

36. Herlemann DP, Labrenz M, Jurgens K, Bertilsson S, Waniek JJ, Andersson AF. Transitions in bacterial communities along the $2000 \mathrm{~km}$ salinity gradient of the Baltic Sea. ISME J. 2011:5:1571-9.

37. Hugerth LW, Wefer HA, Lundin S, Jakobsson HE, Lindberg M, Rodin S, Engstrand L, Andersson AF. DegePrime, a program for degenerate primer design for broad-taxonomic-range PCR in microbial ecology studies. Appl Environ Microbiol. 2014;80:5116-23.

38. Lindh MV, Figueroa D, Sjöstedt J, Baltar F, Lundin D, Andersson A, Legrand C, Pinhassi J. Transplant experiments uncover Baltic Sea basin-specific responses in bacterioplankton community composition and metabolic activities. Front Microbiol. 2015;6:223.

39. Edgar RC. UPARSE: highly accurate OTU sequences from microbial amplicon reads. Nat Methods. 2013:10:996-8.

40. Quast C, Pruesse E, Yilmaz P, Gerken J, Schweer T, Yarza P, Peplies J, Glöckner FO. The SILVA ribosomal RNA gene database project: improved data processing and web-based tools. Nucleic Acids Res. 2013:41:D590-6.

41. Robertson CE, Harris JK, Wagner BD, Granger D, Browne K, Tatem B, Feazel LM, Park K, Pace NR, Frank DN. Explicet: graphical user interface software for metadata-driven management, analysis and visualization of microbiome data. Bioinformatics. 2013;29:3100-1.

42. Kumar S, Stecher G, Tamura K. MEGA7: molecular evolutionary genetics analysis version 7.0 for bigger datasets. Mol Biol Evol. 2016;33:1870-4.

43. Tamura K, Stecher G, Peterson D, Filipski A, Kumar S. MEGA6: molecular evolutionary genetics analysis version 6.0. Mol Biol Evol. 2013;30:2725-9.

44. Pandit SN, Kolasa J, Cottenie K. Contrasts between habitat generalists and specialists: an empirical extension to the basic metacommunity framework. Ecology. 2009;90:2253-62.

45. Martin M. Cutadapt removes adapter sequences from high-throughput sequencing reads. EMB Net J. 2011;17:10-2.

46. Kopylova E, Noé L, Touzet H. SortMeRNA: fast and accurate filtering of ribosomal RNAs in metatranscriptomic data. Bioinformatics. 2012;28: 3211-7.

47. Boisvert S, Laviolette F, Corbeil J. Ray: simultaneous assembly of reads from a mix of high-throughput sequencing technologies. J Comput Biol. 2010;17: 1519-33.

48. Seemann T. Prokka: rapid prokaryotic genome annotation. Bioinformatics. 2014;30:2068-9.

49. Li H, Handsaker B, Wysoker A, Fennell T, Ruan J, Homer N, Marth G, Abecasis $\mathrm{G}$, Durbin R. The sequence alignment/map format and SAMtools. Bioinformatics. 2009;25:2078-9.

50. Langmead B, Trapnell C, Pop M, Salzberg SL. Ultrafast and memory-efficient alignment of short DNA sequences to the human genome. Genome Biol. 2009;10:R25

51. Quinlan AR, Hall IM. BEDTools: a flexible suite of utilities for comparing genomic features. Bioinformatics. 2010;26:841-2.

52. Bolger AM, Lohse $M$, Usadel B. Trimmomatic: a flexible trimmer for Illumina sequence data. Bioinformatics. 2014;30:2114-20.

53. Haas BJ, Papanicolaou A, Yassour M, Grabherr M, Blood PD, Bowden J, Couger MB, Eccles D, Li B, Lieber $M$, et al. De novo transcript sequence reconstruction from RNA-seq using the trinity platform for reference generation and analysis. Nat Protoc. 2013;8:1494-512.

54. Li B, Dewey C. RSEM: accurate transcript quantification from RNA-Seq data with or without a reference genome. BMC Bioinformatics. 2011:12:323.

55. Robinson MD, McCarthy DJ, Smyth GK. edgeR: a bioconductor package for differential expression analysis of digital gene expression data. Bioinformatics. 2010;26:139-40.

56. Lindh MV, Sjöstedt J, Andersson AF, Baltar F, Hugerth LW, Lundin D, Muthusamy S, Legrand C, Pinhassi J. Disentangling seasona bacterioplankton population dynamics by high-frequency sampling. Environ Microbiol. 2015;17:2459-76.

57. Sunagawa S, Coelho LP, Chaffron S, Kultima JR, Labadie K, Salazar G, Djahanschiri B, Zeller G, Mende DR, Alberti A, et al. Structure and function of the global ocean microbiome. Science. 2015;348
58. Rocca JD, Hall EK, Lennon JT, Evans SE, Waldrop MP, Cotner JB, Nemergut DR, Graham EB, Wallenstein MD. Relationships between protein-encoding gene abundance and corresponding process are commonly assumed yet rarely observed. ISME J. 2015;9:1693-9.

59. Harada M, Yoshida T, Kuwahara H, Shimamura S, Takaki Y, Kato C, Miwa T, Miyake H, Maruyama T. Expression of genes for sulfur oxidation in the intracellular chemoautotrophic symbiont of the deep-sea bivalve Calyptogena okutanii. Extremophiles. 2009;13:895-903.

60. Hedderich R, Berkessel A, Thauer RK. Purification and properties of heterodisulfide reductase from Methanobacterium thermoautotrophicum (strain Marburg). Eur J Biochem. 1990;193:255-61.

61. Quatrini R, Appia-Ayme C, Denis Y, Jedlicki E, Holmes DS, Bonnefoy V. Extending the models for iron and sulfur oxidation in the extreme acidophile Acidithiobacillus ferrooxidans. BMC Genomics. 2009;10:394.

62. Dopson M, Johnson DB. Biodiversity, metabolism and applications of acidophilic sulfur-metabolizing microorganisms. Environ Microbiol. 2012; 14:2620-31

63. Hensel M, Hinsley AP, Nikolaus T, Sawers G, Berks BC. The genetic basis of tetrathionate respiration in Salmonella typhimurium. Mol Microbiol. 1999:32:275-87.

64. Mander GJ, Pierik AJ, Huber H, Hedderich R. Two distinct heterodisulfide reductase-like enzymes in the sulfate-reducing archaeon Archaeoglobus profundus. Eur J Biochem. 2004;271:1106-16.

65. Elshahed MS, Najar FZ, Roe BA, Oren A, Dewers TA, Krumholz LR. Survey of archaeal diversity reveals an abundance of halophilic Archaea in a low-salt, sulfide- and sulfur-rich spring. Appl Environ Microbiol. 2004:70:2230-9.

66. Sinkko H, Lukkari K, Sihvonen LM, Sivonen K, Leivuori M, Rantanen M, Paulin $L$, Lyra C. Bacteria contribute to sediment nutrient release and reflect progressed eutrophication-driven hypoxia in an organic-rich continental sea. PLoS One. 2013;8:e67061.

67. Geelhoed JS, Sorokin DY, Epping E, Tourova TP, Banciu HL, Muyzer G, Stams AJ, van Loosdrecht MC. Microbial sulfide oxidation in the oxic-anoxic transition zone of freshwater sediment: involvement of lithoautotrophic Magnetospirillum strain J10. FEMS Microbiol Ecol. 2009:70:54-65.

68. Canfield DE, Stewart FJ, Thamdrup B, De Brabandere L, Dalsgaard T, Delong EF, Revsbech NP, Ulloa O. A cryptic sulfur cycle in oxygen-minimum-zone waters off the Chilean coast. Science. 2010;330:1375.

69. Mills JV, Antler G, Turchyn AV. Geochemical evidence for cryptic sulfur cycling in salt marsh sediments. Earth Planet Sci Lett. 2016:453:23-32.

70. Schedel M, Vanselow M, Trüper HG. Siroheme sulfite reductase isolated from Chromatium vinosum. Purification and investigation of some of its molecular and catalytic properties. Arch Microbiol. 1979;121:29-36.

71. Park S-J, Ghai R, Martín-Cuadrado A-B, Rodríguez-Valera F, Jung M-Y, Kim J$\mathrm{G}$, Rhee S-K. Draft genome sequence of the sulfur-oxidizing bacterium "Candidatus Sulfurovum sediminum" AR, which belongs to the Epsilonproteobacteria. J Bacteriol. 2012:194:4128-9.

72. Pjevac P, Kamyshny A Jr, Dyksma S, Mussmann M. Microbial consumption of zero-valence sulfur in marine benthic habitats. Environ Microbiol. 2014;16: 3416-30.

73. Han Y, Perner M. The globally widespread genus Sulfurimonas: versatile energy metabolisms and adaptations to redox clines. Front Microbiol. 2015; 6:989.

74. Inagaki F, Takai K, Nealson KH, Horikoshi K. Sulfurovum lithotrophicum gen. Nov., sp. nov., a novel sulfur-oxidizing chemolithoautotroph within the $\varepsilon^{-}$ Proteobacteria isolated from Okinawa trough hydrothermal sediments. Int J Syst Evol Microbiol. 2004:54:1477-82.

75. Hanson RS, Hanson TE. Methanotrophic bacteria. Microbiol Rev. 1996;60: 439-71.

76. Havelsrud OE, Haverkamp TH, Kristensen T, Jakobsen KS, Rike AG. A metagenomic study of methanotrophic microorganisms in coal oil point seep sediments. BMC Microbiol. 2011:11:221.

77. Hulthe G, Hulth S, Hall POJ. Effect of oxygen on degradation rate of refractory and labile organic matter in continental margin sediments. Geochim Cosmochim Acta. 1998;62:1319-28.

78. Conley DJ. Ecology: save the Baltic Sea. Nature. 2012;486:463-4.

79. Stigebrandt A, Gustafsson BG. Improvement of Baltic proper water quality using large-scale ecological engineering. Ambio. 2007;36:280-6. 
80. Stigebrandt A, Liljebladh B, de Brabandere L, Forth M, Granmo Å, Hall P, Hammar J, Hansson D, Kononets M, Magnusson M, et al. An experiment with forced oxygenation of the deepwater of the anoxic by fjord, western Sweden. Ambio. 2015:44:42-54

81. Conley DJ, Humborg C, Rahm L, Savchuk OP, Wulff F. Hypoxia in the Baltic Sea and basin-scale changes in phosphorus biogeochemistry. Environ Sci Technol. 2002;36:5315-20.

Submit your next manuscript to BioMed Central and we will help you at every step:

- We accept pre-submission inquiries

- Our selector tool helps you to find the most relevant journal

- We provide round the clock customer support

- Convenient online submission

- Thorough peer review

- Inclusion in PubMed and all major indexing services

- Maximum visibility for your research

Submit your manuscript at www.biomedcentral.com/submit 